\title{
The Impact of Abyssal Mixing Parameterizations in an Ocean General Circulation Model
}

\author{
STEVEN R. JAYNE \\ Physical Oceanography Department, Woods Hole Oceanographic Institution, Woods Hole, Massachusetts
}

(Manuscript received 27 June 2008, in final form 15 December 2008)

\begin{abstract}
A parameterization of vertical diffusivity in ocean general circulation models has been implemented in the ocean model component of the Community Climate System Model (CCSM). The parameterization represents the dynamics of the mixing in the abyssal ocean arising from the breaking of internal waves generated by the tides forcing stratified flow over rough topography. This parameterization is explored over a range of parameters and compared to the more traditional ad hoc specification of the vertical diffusivity.

Diapycnal mixing in the ocean is thought to be one of the primary controls on the meridional overturning circulation and the poleward heat transport by the ocean. When compared to the traditional approach with uniform mixing, the new mixing parameterization has a noticeable impact on the meridional overturning circulation; while the upper limb of the meridional overturning circulation appears to be only weakly impacted by the transition to the new parameterization, the deep meridional overturning circulation is significantly strengthened by the change. The poleward ocean heat transport does not appear to be strongly affected by the mixing in the abyssal ocean for reasonable parameter ranges. The transport of the Antarctic Circumpolar Current through the Drake Passage is related to the amount of mixing in the deep ocean. The new parameterization is found to be energetically consistent with the known constraints on the ocean energy budget.
\end{abstract}

\section{Introduction}

Mixing in the ocean is a critical process determining the circulation and properties of the ocean. It occurs at the smallest spatial scales and is the end result of a variety of different dynamical processes ranging from eddy stirring, wave breaking, and turbulent mixing down to molecular diffusion. Since this process is unresolved in ocean general circulation models (OGCMs), it must be correctly parameterized, and that is one of the greatest challenges in physical oceanography today. In the abyssal ocean, where the velocity field is generally small, correct parameterization of the mixing dynamics is critical to correctly modeling the ocean state. There are numerous recent reviews on various aspects of abyssal mixing in the ocean (Munk and Wunsch 1998; Garrett and St. Laurent 2002; Huang 2004; Jayne et al. 2004; Wunsch and Ferrari 2004; Garrett and Kunze 2007), and the reader is referred to them for a more

Corresponding author address: S. R. Jayne, Physical Oceanography Department, Woods Hole Oceanographic Institution, MS 21, 360 Woods Hole Road, Woods Hole, MA 02543-1541.

E-mail: surje@alum.mit.edu general discussion of ocean mixing, its energetics, and its relationship to the ocean's circulation.

Most OGCMs use a parameterization for the vertical diffusivities based on that originally utilized by Bryan and Lewis (1979) in one of the first global OGCM experiments, so it is instructive to consider the motivation for that original diffusivity profile. Bryan and Lewis (1979) formulated their parameterization to be consistent with Gregg (1977), who observed that vertical mixing was lowest in the main thermocline and generally increased below it, and with Munk (1966), who had estimated based on tracer observations that the spatially averaged diffusivity of the interior ocean (excluding the upper and lower $1 \mathrm{~km}$ ) was about $1.3 \times 10^{-4} \mathrm{~m}^{2} \mathrm{~s}^{-1}$. Bryan and Lewis (1979) therefore chose their vertical diffusivity $\kappa_{\nu}$ to be a function of depth, $z$ (meters), with the form

$$
\kappa_{\nu}(z)=\left[0.8+\frac{1.05}{\pi} \tan ^{-1}\left(\frac{z-2500}{222.2}\right)\right] \times 10^{-4} \mathrm{~m}^{2} \mathrm{~s}^{-1}
$$

which gives a value of $0.3 \times 10^{-4} \mathrm{~m}^{2} \mathrm{~s}^{-1}$ for the diffusivity in the upper ocean, and a value of $1.3 \times 10^{-4} \mathrm{~m}^{2} \mathrm{~s}^{-1}$ for 
the deep ocean, with a smooth transition at a depth of $2500 \mathrm{~m}$. More recent OGCMs have used modifications of the Bryan and Lewis (1979) profile, generally with changes to the parameters, but with the same functional shape. For example, the Community Climate Simulation Model (CCSM) ocean component model uses a form similar to Eq. (1), but with an upper-ocean value of $0.1 \times$ $10^{-4} \mathrm{~m}^{2} \mathrm{~s}^{-1}$ and a deep-ocean value of $1.0 \times 10^{-4} \mathrm{~m}^{2} \mathrm{~s}^{-1}$, with the transition depth at $1000 \mathrm{~m}$. However, there is no observational evidence to suggest that the mixing in the ocean is horizontally uniform, and indeed there is significant evidence that it is heterogeneous with spatial variations of several orders of magnitude in its intensity (Polzin et al. 1997; Ganachaud 2003).

After Bryan and Lewis (1979), the subject of the effect of the vertical diffusivity on the simulated circulation was studied extensively, and, with the widespread adoption of OGCMs as a research tool, there have been a wide variety of suggested parameterizations for the vertical diffusivity. Most of these studies have focused on the impact on the simulated large-scale ocean circulation as their measure of improvement for the proposed parameterization. In particular they generally focus on the meridional overturning circulation (MOC) and the ocean's poleward transport of heat as metrics to judge improvements in the models.

The simplest parameterization of the vertical diffusivity specifies the diffusivity as a function of depth only, with no horizontal or temporal variations, and in the purest case uses a uniform constant for the entire ocean volume. Bryan (1987) examined the impact of varying the value of a vertically constant diffusivity in an idealized sector ocean. In that study, the vertical diffusivity was varied over the range of $0.1-5 \times 10^{-4} \mathrm{~m}^{2} \mathrm{~s}^{-1}$, and it was found that the strength of the MOC followed the value of the diffusivity with an approximately cube root power law, and that the poleward heat transport also increased with increasing diffusivity. From this study it was concluded that the ocean's MOC and poleward heat transport is a strong function of the ocean's diapycnal diffusivity.

A more complicated diapycnal mixing parameterization was proposed by Gargett (1984; see also Cummins et al. 1990; Hirst and Cai 1994), who argued that the value of diffusivity should vary as an inverse power-law function of the stratification $N$, generally as $\kappa_{\nu} \sim N^{-n}$, and specifically with $n=1$ being considered in their modeling studies. This formulation allows the vertical mixing in the model to be fully interactive with the evolving ocean state, varying as a function of threedimensional space and time. In general, they found that using this form for the vertical mixing did not result in major changes to the modeled circulation compared to a control run with a small globally constant diffusivity.
Rather, more modest changes were seen: an increase in abyssal temperatures and salinities, a strengthening of the MOC, and a strengthening of the abyssal stratification. However, the ocean's poleward heat transport was largely unchanged. At the other extreme of mixing parameterizations, studies have found that sensible circulations could be found for a sector model with no explicit vertical mixing in the interior ocean and mixing confined only to the ocean basin's lateral boundaries (Marotzke 1997; Samelson 1998). Moreover, Scott and Marotzke (2002) found that boundary mixing was much more efficient at driving a strong MOC than mixing in the interior of the ocean.

Direct observations of mixing in the abyssal ocean were obtained in the Brazil Basin Experiment (Polzin et al. 1997; Ledwell et al. 2000), and indeed that work is the motivation for much of the recent efforts toward improving mixing parameterizations in OGCMs. The observational evidence suggested that diapycnal mixing in the abyssal ocean was weak (less than $0.1 \times 10^{-4} \mathrm{~m}^{2} \mathrm{~s}^{-1}$ ) over areas of smooth bottom topography and was strongly enhanced in regions of rough topography (exceeding $5 \times 10^{-4} \mathrm{~m}^{2} \mathrm{~s}^{-1}$ above the Mid-Atlantic Ridge) (Polzin et al. 1997; Ledwell et al. 2000; Morris et al. 2001; St. Laurent et al. 2001).

The first attempt to include a parameterization of enhanced mixing over rough topography was by Hasumi and Suginohara (1999), who implemented a scheme where the vertical mixing was enhanced to a value of $100 \times 10^{-4} \mathrm{~m}^{2} \mathrm{~s}^{-1}$ (decaying exponentially in the vertical away from the bottom) in grid cells that were determined to exceed a given topographic roughness threshold. This was an ad hoc approach to correlate enhanced mixing with areas of high baroclinic tidal energy. Overall, they found only small changes in the abyssal circulation, though there was a notable enhancement in the abyssal stratification in the simulations with the enhanced mixing over rough topography. In a smaller domain, considering only the South Atlantic Ocean, Huang and Jin (2002) experimented with an ad hoc enhancement of diffusivity along the MidAtlantic Ridge and found that locally enhanced diffusivity could significantly alter the circulation that would be expected from the theory of Stommel and Arons (1960) with uniform mixing.

Taken together the observational evidence and model results suggest that the parameterized vertical mixing is an important control on the ocean's circulation; it is not properly parameterized by the simple parameterizations in OGCMs; and, furthermore, parameterizing it properly is of utmost importance if OGCMs are to correctly model the ocean's circulation. A critical concern for OGCMs should be the need for them to obey 
the laws of thermodynamics and respect conservation of energy. As Huang (1999) correctly argues, one must consider the energy required by any mixing parameterization in its formulation and what source supplies that energy. Mixing parameterizations such as the Bryan and Lewis (1979) specification do not take into account the mechanical energy required to mix the ocean. Diapycnal mixing in the ocean increases the potential energy of the water and in doing so consumes mechanical energy. This mechanical energy must be provided by a source, either the surface wind stress and/or the tides (Munk and Wunsch 1998). The ocean is not a heat engine and, indeed, the MOC cannot exist without a mechanical energy source to drive it (Wunsch and Ferrari 2004).

It was these considerations that led, through a series of papers, to the development of a parameterization to improve the representation of abyssal mixing in OGCMs. Based on the observation that mixing rates over rough topography are enhanced (Polzin et al. 1997; Ledwell et al. 2000) and inverse models of the tides that suggested enhanced energy loss from the barotropic tides over rough topography (Egbert and Ray 2000), Jayne and St. Laurent (2001) applied a parameterization for topographic drag in a model of the barotropic tides and found that it improved the simulated tides. This parameterization represents the physics of the conversion of tidal energy into internal wave energy and is similar to the topographic drag parameterization used in atmospheric models (Palmer et al. 1986; McFarlane 1987). Furthermore, it provides a map of the energy conversion from the barotropic tide into internal waves, and this map is then used in a parameterization for the vertical mixing of St. Laurent et al. (2002), which relates the amount of internal wave energy to a turbulent dissipation rate and from that an estimated diffusivity using the Osborn (1980) relation. The resulting tidal mixing parameterization has an explicit dependence on the stratification of the same form proposed by Gargett (1984) but accounts for the spatially varying energy dissipation. Following on this path, the parameterization was then used in a coarse-resolution OGCM by Simmons et al. (2004). They found reduced temperature and salinity biases in the model version using the new parameterization compared to control cases using either a globally constant $0.9 \times 10^{-4} \mathrm{~m}^{2} \mathrm{~s}^{-1}$ or the Bryan and Lewis (1979) formulation. However, it should be noted that their control case with $0.9 \times 10^{-4} \mathrm{~m}^{2} \mathrm{~s}^{-1}$ is not realistic in that the high mixing extends all the way up through the water column in direct conflict with observations of mixing in the upper ocean (Gregg 1987; Ledwell et al. 1993, 1998).

Saenko and Merryfield (2005) also utilized the St. Laurent et al. (2002) parameterization in a study sim- ilar to Simmons et al. (2004). They found three important impacts from including the tidal mixing parameterization in their OGCM: first, that without enhanced abyssal mixing the North Pacific becomes unstratified with little circulation; second, that the tidal parameterization leads to a stronger and deeper Antarctic Circumpolar Current in the model; and, finally, that the tidal mixing parameterization did not significantly affect the ocean's poleward heat transport or the formation of deep water formed in the North Atlantic Ocean. Saenko (2006) adopted a simplified version of the tidal mixing parameterization in a sector ocean model and found that simulated ocean circulation was heavily dependent on the horizontal distribution of the vertical mixing. For cases in which the mixing in the upper ocean was small $\left(0.1 \times 10^{-4} \mathrm{~m}^{2} \mathrm{~s}^{-1}\right)$, despite changes to the vertical mixing in the deep ocean, the integral quantities like the MOC and poleward heat transport were not significantly different, though the details of the horizontal circulation were quite different. Furthermore, they concluded that it was difficult to reconcile basin-averaged diffusivities on the order of $10 \times 10^{-4} \mathrm{~m}^{2} \mathrm{~s}^{-1}$ as estimated by Ganachaud and Wunsch (2000) with realistic stratification in the deep ocean unless the strong vertical mixing is confined to a few locations.

The goal of this study is to understand the sensitivity of an OGCM to the details of the parameterization of St. Laurent et al. (2002) and, more generally, to investigate the role of abyssal tidal mixing in the general circulation of the ocean. We compare simulations with various parameter choices in a large suite of simulations with the traditional parameterization over a range of parameter values. In this work, we further explore the vertical mixing parameterization of tidally driven mixing developed in Jayne and St. Laurent (2001) and St. Laurent et al. (2002) and implemented by Simmons et al. (2004). In particular we wish to understand the importance of some of the parameter choices that were made in that work. Further, we wish to understand some of the sensitivities in the simulated ocean circulation that were seen in their work. Finally, we wish to gain a better understanding of what drives the strength of the MOC in OGCMs and the interaction of vertical diffusivity with the ocean's general circulation. In section 2 , we describe the model configuration and experiments, in section 3 we summarize the results of the model experiments, and in section 4 we discuss the general conclusions of the work.

\section{Model configuration and experiments}

The ocean model used is these experiments is the Los Alamos National Laboratory's Parallel Ocean Program 
(POP 1.4.3) (Smith et al. 1992) that is the ocean component of the Community Climate System Model, version 3 (CCSM3; see Smith and Gent 2002; Collins et al. 2006; Danabasoglu et al. 2006; Gent et al. 2006, for a description), which is based at the National Center for Atmospheric Research (NCAR). The model has a levelcoordinate, Boussinesq, hydrostatic dynamical core that solves the primitive equations on a global grid, with the northern numerical grid pole displaced into Greenland. There are multiple parameterizations of mixing phenomena in the model (as well as numerical mixing); however, here we are only concerned with the vertical mixing in the interior away from the surface boundary layer. The mixing in the surface ocean is largely driven by the $K$-profile parameterization (KPP; Large et al. 1994) and is left unchanged in this set of experiments. Convective mixing in instances of unstable stratification is left unaltered as well.

The vertical mixing parameterization of St. Laurent et al. (2002) was implemented in a similar fashion as in Simmons et al. (2004) as

$$
\kappa_{\nu}(x, y, z, t)=\kappa_{0}+\frac{\Gamma \varepsilon}{N^{2}}=\left[0.1+\frac{q \Gamma E(x, y) F(z)}{\rho N^{2}(x, y, z, t)}\right] .
$$

The parameterization for the vertical diffusivity is related to the turbulent dissipation using the Osborn (1980) relation. The mixing efficiency of turbulence is set by $\Gamma$ and is taken to be the canonical value of $\Gamma=0.2$ (Osborn 1980). The tidal dissipation efficiency is given by the parameter $q=1 / 3$ and represents the part of the internal wave energy flux $E(x, y)$ that is dissipated locally (St. Laurent and Garrett 2002). The rest of the internal wave energy $(1-q=2 / 3)$ is presumed to radiate to the far field and contribute to the background internal wave field (Garrett and Munk 1975). The vertical structure function $F(z)$ models the distribution of the turbulent mixing in the vertical and is implemented as a simple exponential decaying upward away from the bottom, with a vertical scale of $\zeta=500 \mathrm{~m}$ (St. Laurent and Nash 2004),

$$
F(z)=\frac{e^{(z-H) / \zeta}}{\zeta\left(1-e^{-H / \zeta}\right)},
$$

and is normalized so that vertical integral over the water column is unity (St. Laurent et al. 2002).

The constant background value of $\kappa_{0}=0.1 \times 10^{-4} \mathrm{~m}^{2} \mathrm{~s}^{-1}$ is an attempt to model the low-level of mixing in the ocean in areas away from topography (Gregg 1987). Exactly what contributes the mechanical energy required to maintain the $0.1 \times 10^{-4} \mathrm{~m}^{2} \mathrm{~s}^{-1}$ background diffusivity is less clear. However, it is the order of magnitude expected from the self-interaction of the background Garrett-Munk internal wave spectrum (Gregg 1987, 1989; Hibiya et al. 2006). The extent to which the model can achieve a small value for mixing is unclear, as spurious numerical mixing may be larger than the prescribed $0.1 \times 10^{-4} \mathrm{~m}^{2} \mathrm{~s}^{-1}$ and will be larger in higher-resolution models (Griffies et al. 2000). However, experiments performed with CCSM that utilize smaller background levels of the vertical mixing near the equator $\left(\kappa_{0}=0.01 \times 10^{-4} \mathrm{~m}^{2} \mathrm{~s}^{-1}\right)$ show marked changes in the simulated climate (Jochum 2009), suggesting that the model is capable of achieving small background values of the mixing.

The vertical viscosity is calculated from the vertical diffusivity assuming a Prandtl number of 10, as is done in the standard mixing in CCSM (and is standardly done in the KPP mixing scheme; Large et al. 1994). In the limit of $N \rightarrow 0$ (or becoming negative), both the vertical diffusivity and viscosity are capped at $1000 \times 10^{-4} \mathrm{~m}^{2} \mathrm{~s}^{-1}$, which are the model's default values for diffusivity and viscosity for convective mixing (i.e., the Prandtl number is 1 for purely convective mixing). This is a departure from Simmons et al. (2004), who instead impose a lower limit on $N^{2}$ of $10^{-8} \mathrm{~s}^{-2}$ (additionally, convective mixing was used to limit negative stratification regions), and Saenko and Merryfield (2005), who cap $\kappa_{\nu}$ to be less than $20 \times 10^{-4} \mathrm{~m}^{2} \mathrm{~s}^{-1}$. Capping the diffusivity changes the energy consistency of the scheme, and for this study we desired to keep energy consistency. One other change was that the parameterization was applied everywhere, compared to Simmons et al. (2004), who arbitrarily limited it to depths greater than a $1000 \mathrm{~m}$. The conversion of tidal energy into internal waves that occurs in the deep ocean also occurs along the shelf break; therefore, we removed the depth cutoff.

The internal wave energy map, $E(x, y)$ in Eq. (2), is derived in a similar manner as in Jayne and St. Laurent (2001) from a barotropic model of the tides utilizing a parameterization of the conversion of barotropic tidal energy into internal waves. The essential goal of the parameterization is to represent the momentum exchange between the barotropic tides and the unrepresented internal waves induced by the tidal flow over rough topography in a stratified ocean. In the parameterization of Jayne and St. Laurent (2001), the conversion of barotropic tidal kinetic energy is given by

$$
E(x, y) \sim \frac{1}{2} \rho_{0} k h^{2} N|\mathbf{u}|^{2},
$$

for the energy flux per unit area $E$, where $N$ is the buoyancy frequency, $(k, h)$ are the wavenumber and 


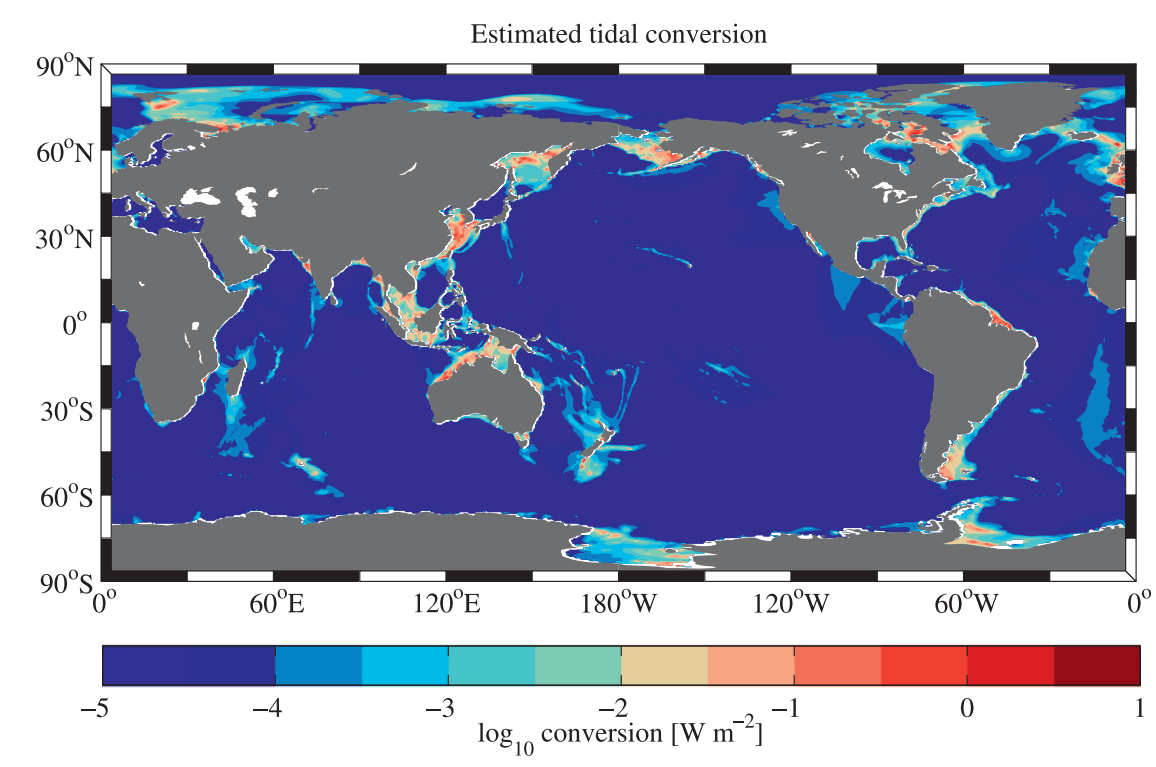

FIG. 1. Estimated conversion of barotropic tidal energy into internal waves from a barotropic tide model using the parameterization given in Eq. (4).

amplitude that characterize the bathymetry, and $\mathbf{u}$ is the barotropic tidal velocity vector. The topographic roughness $h^{2}$ is derived from the high-resolution bathymetry [2-minute gridded elevations/bathymetry for the world (ETOPO2v2); see Smith and Sandwell 1997; U.S. Department of Commerce 2006] as the root-mean-square of the topography over a 50-km smoothing radius, and $k$ is a free parameter set as $k=2 \pi / 125 \mathrm{~km}$. It should be emphasized that Eq. (4) is a scale relation and not a precise specification of internal tide energy flux. In the barotropic tidal model, the value of $k$ was tuned to give the best fit to the observed tides.

Some modifications have been made to update the Jayne and St. Laurent (2001) methodology. In particular, the tide model's domain has been expanded to cover the global ocean (rather than $\pm 72^{\circ}$ as in the original work). Additionally, the gravitational self-attraction and loading term in the tidal model has been implemented using an iterative method (Egbert et al. 2004; Arbic et al. 2004). These changes improve the overall fit of the simulated tides compared to Jayne and St. Laurent (2001), with the error variance of the modeled tides to the observed tides reduced by $21 \%$. The diurnal tides improved significantly, with a variance reduction of $66 \%$ (likely due to including all of the Southern Ocean, where the diurnal tides are large), while the simulated semidiurnal tides did not improve. Other parameterizations for the internal wave conversion in place of Eq. (4) been suggested (Carrère and Lyard 2003; Arbic et al. 2004; Egbert et al. 2004); however, it was found that any of these schemes gave comparable accuracies in the simulated tidal elevations once they were tuned (Egbert et al. 2004). Tangentially, this may indicate that, as long as there is a suitably tuned parameterization of the internal wave drag in tide models, the accuracy of the simulated tides may not be limited by the dynamical models but rather by uncertainty in the ocean bottom topography (Egbert et al. 2004). Moreover, it also means that it is difficult to discern improvements in the formulation of internal wave conversion parameterizations based on RMS differences between the modeled tidal and the observed tide.

As in Jayne and St. Laurent (2001), the total of the global dissipation and conversion of tidal energy in the barotropic tide model is $3.49 \mathrm{TW}$, of which $1.50 \mathrm{TW}$ is dissipated by the cubic drag, largely in shallow seas, and $1.99 \mathrm{TW}$ is scattered by conversion of the barotropic tide into internal waves. Of the $1.99 \mathrm{TW}$ of internal wave conversion energy, $1.00 \mathrm{TW}$ occurs in the ocean deeper than $1000 \mathrm{~m}$, while $0.99 \mathrm{TW}$ of the internal wave conversion occurs in areas shallower than $1000 \mathrm{~m}$. The map of $E(x, y)$ is shown in Fig. 1 and is interpolated onto the model grid and used in Eq. (2).

\section{a. Low-resolution runs}

The majority of the experiments presented here were performed with the coarse-resolution $\left(\approx 3^{\circ}\right)$ version of the model, which was integrated synchronously for $5000 \mathrm{yr}$ (i.e., with no time acceleration of tracers relative to momentum). The ocean model was initialized with World Ocean Atlas 1998 climatology (Levitus et al. 1998) merged with Polar Science Center Hydrographic 
TABLE 1. Summary of physical parameters and numerics for model runs described in the text.

\begin{tabular}{|c|c|c|c|}
\hline Case & $\kappa_{\nu}$ & Forcing & Advection \\
\hline $\mathrm{A}$ & $0.1 \rightarrow 1.0($ deep $) \times 10^{-4} \mathrm{~m}^{2} \mathrm{~s}^{-1}$ & Normal year $+5 \mathrm{~W} \mathrm{~m}^{-2}$ & Upwind \\
\hline $\mathrm{B}$ & $0.1 \rightarrow 0.5$ (deep) $\times 10^{-4} \mathrm{~m}^{2} \mathrm{~s}^{-1}$ & Normal year $+5 \mathrm{~W} \mathrm{~m}^{-2}$ & Upwind \\
\hline $\mathrm{C}$ & $0.1 \rightarrow 2.0($ deep $) \times 10^{-4} \mathrm{~m}^{2} \mathrm{~s}^{-1}$ & Normal year $+5 \mathrm{~W} \mathrm{~m}^{-2}$ & Upwind \\
\hline $\mathrm{D}$ & $0.1 \rightarrow 5.0($ deep $) \times 10^{-4} \mathrm{~m}^{2} \mathrm{~s}^{-1}$ & Normal year $+5 \mathrm{~W} \mathrm{~m}^{-2}$ & Upwind \\
\hline $\mathrm{E}$ & $0.3 \rightarrow 1.3($ deep $) \times 10^{-4} \mathrm{~m}^{2} \mathrm{~s}^{-1}$ & Normal year $+5 \mathrm{~W} \mathrm{~m}^{-2}$ & Upwind \\
\hline $\mathrm{F}$ & $0.1 \times 10^{-4} \mathrm{~m}^{2} \mathrm{~s}^{-1}$ & Normal year $+5 \mathrm{~W} \mathrm{~m}^{-2}$ & Upwind \\
\hline G & $0.5 \times 10^{-4} \mathrm{~m}^{2} \mathrm{~s}^{-1}$ & Normal year $+5 \mathrm{~W} \mathrm{~m}^{-2}$ & Upwind \\
\hline $\mathrm{H}$ & $1.0 \times 10^{-4} \mathrm{~m}^{2} \mathrm{~s}^{-1}$ & Normal year $+5 \mathrm{~W} \mathrm{~m}^{-2}$ & Upwind \\
\hline $\mathrm{I}$ & $2.0 \times 10^{-4} \mathrm{~m}^{2} \mathrm{~s}^{-1}$ & Normal year $+5 \mathrm{~W} \mathrm{~m}^{-2}$ & Upwind \\
\hline $\mathrm{J}$ & $5.0 \times 10^{-4} \mathrm{~m}^{2} \mathrm{~s}^{-1}$ & Normal year $+5 \mathrm{~W} \mathrm{~m}^{-2}$ & Upwind \\
\hline K & Tidal & Normal year $+5 \mathrm{~W} \mathrm{~m}^{-2}$ & Upwind \\
\hline $\mathrm{L}$ & $1 / 2 \times$ Tidal $(q=1 / 6)$ & Normal year $+5 \mathrm{~W} \mathrm{~m}^{-2}$ & Upwind \\
\hline M & $2 \times$ Tidal $(q=2 / 3)$ & Normal year $+5 \mathrm{~W} \mathrm{~m}^{-2}$ & Upwind \\
\hline $\mathrm{N}$ & $5 \times$ Tidal $(q=5 / 3)$ & Normal year $+5 \mathrm{~W} \mathrm{~m}^{-2}$ & Upwind \\
\hline $\mathrm{O}$ & $0.1 \rightarrow 1.0($ deep $) \times 10^{-4} \mathrm{~m}^{2} \mathrm{~s}^{-1}$ & Strong surface restoring & Upwind \\
\hline $\mathrm{P}$ & $1.0 \times 10^{-4} \mathrm{~m}^{2} \mathrm{~s}^{-1}$ & Strong surface restoring & Upwind \\
\hline Q & Tidal & Strong surface restoring & Upwind \\
\hline $\mathrm{R}$ & Tidal & Normal year (no correction) & Upwind \\
\hline S & Tidal & Normal year $+10 \mathrm{~W} \mathrm{~m}^{-2}$ & Upwind \\
\hline $\mathrm{T}$ & Tidal $(\zeta=50 \mathrm{~m})$ & Normal year $+5 \mathrm{~W} \mathrm{~m}^{-2}$ & Upwind \\
\hline $\mathrm{U}$ & Tidal & Normal year $+5 \mathrm{~W} \mathrm{~m}^{-2}$ & Centered \\
\hline $\mathrm{W}$ & Tidal $\left(\kappa_{\nu}<100 \times 10^{-4} \mathrm{~m}^{2} \mathrm{~s}^{-1}\right)$ & Normal year $+5 \mathrm{~W} \mathrm{~m}^{-2}$ & Upwind \\
\hline $\mathrm{X}$ & Tidal $\left(\kappa_{\nu}<50 \times 10^{-4} \mathrm{~m}^{2} \mathrm{~s}^{-1}\right)$ & Normal year $+5 \mathrm{~W} \mathrm{~m}^{-2}$ & Upwind \\
\hline $\mathrm{Y}$ & Tidal $\left(\kappa_{\nu}<20 \times 10^{-4} \mathrm{~m}^{2} \mathrm{~s}^{-1}\right)$ & Normal year $+5 \mathrm{~W} \mathrm{~m}^{-2}$ & Upwind \\
\hline $1^{\circ}$ Standard & $0.1 \rightarrow 1.0($ deep $) \times 10^{-4} \mathrm{~m}^{2} \mathrm{~s}^{-1}$ & Normal year (no correction) & Upwind \\
\hline $1^{\circ}$ Tidal & Tidal & Normal year (no correction) & Upwind \\
\hline $1^{\circ}$ Limited & Tidal $\left(\kappa_{\nu}<100 \times 10^{-4} \mathrm{~m}^{2} \mathrm{~s}^{-1}\right)$ & Normal year (no correction) & Upwind \\
\hline
\end{tabular}

Climatology Arctic data (Steele et al. 2001). The lowresolution model has 25 vertical levels, which in the deep ocean are $500 \mathrm{~m}$ thick. A total of 22 simulations were performed using the lower-resolution version of the CCSM ocean model (Table 1). As was noted in the introduction, the POP implementation in CCSM3 uses a modified version of the Bryan and Lewis (1979)-type profile given in Eq. (1) for its specification of the vertical diffusivity, with a value of $0.1 \times 10^{-4} \mathrm{~m}^{2} \mathrm{~s}^{-1}$ in the upper ocean and $1.0 \times 10^{-4} \mathrm{~m}^{2} \mathrm{~s}^{-1}$ in the deep ocean. A simulation with these standard parameters forms our control run (case A). Additional runs were performed varying the abyssal values of the diffusivity profile from 0.5 to $5 \times 10^{-4} \mathrm{~m}^{2} \mathrm{~s}^{-1}$ (cases B, C, and D) and using a vertically constant diffusivity value from 0.1 to 5 $\times 10^{-4} \mathrm{~m}^{2} \mathrm{~s}^{-1}$ (Cases F, G, H, I, and J). An additional case was done using the traditional Bryan and Lewis (1979) profile (case E). These cases are compared with a series of runs using the parameterization for the vertical diffusivity given by Eq. (2) for the basic test case (case $\mathrm{K}$ ) and for a set of scalings of the tidal portion of the mixing (cases $\mathrm{L}, \mathrm{M}$, and $\mathrm{N}$ ), which can be thought of as varying the combined value of $q \Gamma$ in Eq. (2). We also perform a sensitivity test case for an order of magnitude decrease in the depth scale $[\zeta=50 \mathrm{~m}$ in Eq. (3)] of the vertical decay function (case T), though observational evidence suggests that the decay should be roughly 300 $500 \mathrm{~m}$ (St. Laurent and Nash 2004).

Unlike previous studies (Simmons et al. 2004; Saenko and Merryfield 2005), which used strong surface restoring to observed temperature and salinity, the majority of the simulations done here use a more realistic bulk forcing computed from an atmospheric reanalysis and the model state (Large et al. 1997). The model was forced using an annually repeating cycle driving the CCSM flux coupler with the climatological corrected "normal year" forcing of Large and Yeager $(2004,2009)$. After an initial set of experiments were performed, it was noted that the heat flux forcing derived from the normal year was unbalanced relative to observed sea surface temperatures by approximately $5 \mathrm{~W} \mathrm{~m}^{-2}$ over the global ocean, so for the coarse-resolution runs an ad hoc $+5 \mathrm{~W} \mathrm{~m}^{-2}$ was added to the downward longwave radiation flux to prevent the ocean from losing heat over the 5000-yr integrations. Two additional cases were performed with no additional heat flux (i.e., $0 \mathrm{~W} \mathrm{~m}^{-2}$ ) and $+10 \mathrm{~W} \mathrm{~m}^{-2}$ (cases $\mathrm{R}$ and $\mathrm{S}$, respectively). All of the runs utilized a weak restoring to observed sea surface salinity values with a time scale of 8 months over $8 \mathrm{~m}$. Additionally, to understand whether the surface forcing 
of the model was creating differences in the model's behavior compared to Simmons et al. (2004), 3 runs were performed with strong surface restoring in both temperature and salinity with a time scale of 1 day over $8 \mathrm{~m}$ (cases $\mathrm{O}, \mathrm{P}$, and $\mathrm{Q}$, corresponding to the flux-forced cases $\mathrm{A}, \mathrm{H}$, and $\mathrm{K}$, respectively). These runs with strong surface restoring correspond more closely to the configuration of the OGCM in Simmons et al. (2004). Additionally, a simulation was performed using a centered advection scheme (case $\mathrm{U}$ ) rather than the third-order upwind advection scheme to provide a test of the OGCM's sensitivity to other model numerical choices. Finally, a series of three runs (cases W, X, and Y) were done in which the maximum value of $\kappa_{\nu}$ from the tidal mixing was capped at $100 \times 10^{-4} \mathrm{~m}^{2} \mathrm{~s}^{-1}, 50 \times$ $10^{-4} \mathrm{~m}^{2} \mathrm{~s}^{-1}$, and $20 \times 10^{-4} \mathrm{~m}^{2} \mathrm{~s}^{-1}$, respectively (with case $\mathrm{Y}$ being similar to the capping used in Saenko and Merryfield 2005). These cases are summarized in Table 1.

\section{b. Medium-resolution runs}

Three simulations were performed at a medium resolution of approximately $1^{\circ}$ for $500 \mathrm{yr}$. The mediumresolution model has 40 vertical levels, which in the deep ocean are $250 \mathrm{~m}$ thick. As with the low-resolution simulations, these were run using the standard CCSM configuration, with the only difference between the first two of the runs being that the control run used the standard vertical mixing specification and the other used the tidal parameterization for the vertical mixing in the deep ocean. These model runs correspond to the low-resolution cases $\mathrm{A}$ and $\mathrm{K}$. An additional simulation was done with an upper limit on $\kappa_{\nu}$ of $100 \times 10^{-4} \mathrm{~m}^{2} \mathrm{~s}^{-1}$ (corresponding to case W). All of these runs were forced with the same normal-year forcing as the lowresolution runs, except the additional $5 \mathrm{~W} \mathrm{~m}^{-2}$ correction was not added since the $1^{\circ}$ model was more nearly in balance with the flux forcing than the $3^{\circ}$ model. It should be noted that since these runs were only integrated for $500 \mathrm{yr}$, the abyssal temperature field still shows considerable drift at the end of the integration, so they are not in equilibrium.

\section{Results}

Given the large number of simulations that were run, it is impossible to describe them all in detail; however, we will attempt to summarize the characteristics and changes between the simulations. For the low-resolution $\left(\approx 3^{\circ}\right)$ simulations, we will pay particular attention to case a (the standard case), case F (constant $\kappa_{\nu}=0.1 \times$ $10^{-4} \mathrm{~m}^{2} \mathrm{~s}^{-1}$ ), case $\mathrm{H}$ (constant $\kappa_{\nu}=1.0 \times 10^{-4} \mathrm{~m}^{2} \mathrm{~s}^{-1}$ ), and case $\mathrm{K}$ (the tidal mixing parameterization). Simple metrics of the final model state for all the cases are summarized in Table 2.

\section{a. Low-resolution runs}

To assess whether a given model solution is better than another is a difficult task given the inherent uncertainties in trying to integrate a low-resolution ocean model to equilibrium. Errors in the surface forcing, model numerics, and physical parameterizations, and even doubts that the present-day ocean is in equilibrium itself, all compound to make it an ill-posed analysis. We can show this by probing the sensitivity of the model to the effects of changing the surface forcing and advection scheme (summarized in Table 2). Comparing the standard case (case a) and the tidal mixing (case $\mathrm{K}$ ) there is an overall decrease in the volume-averaged potential temperature from $2.91^{\circ} \mathrm{C}$ to $1.77^{\circ} \mathrm{C}$, a change of $1.14^{\circ} \mathrm{C}$. However, changing the surface forcing from the fluxes calculated from the set atmospheric formulation to strong surface restoring, the average temperature for the standard mixing (case O) falls to $1.99^{\circ} \mathrm{C}$, and for the tidal mixing (case $\mathrm{Q}$ ) to $1.43^{\circ} \mathrm{C}$, for changes of $0.92^{\circ}$ and $0.34^{\circ} \mathrm{C}$, respectively. Additionally, changing the adjustment to surface flux forcing by $\pm 5 \mathrm{~W} \mathrm{~m}^{-2}$ for the tidal mixing runs (case $\mathrm{K}$ ) to $0 \mathrm{~W} \mathrm{~m}^{-2}$ (case $\mathrm{R}$ ) and $+10 \mathrm{~W} \mathrm{~m}^{-2}$ (case $\mathrm{S}$ ), yields changes in the volumeaveraged temperature of $0.76^{\circ}$ and $1.04^{\circ} \mathrm{C}$. We see that these uncertainties in the model's parameters, forcing, and physics, which are unrelated to mixing, result in changes to the final ocean state that are of the same order of magnitude as those resulting from the change in the mixing parameterization. Similar changes are seen in the other metrics, such as the strength of the MOC, the heat transport at $25^{\circ} \mathrm{N}$, and the Drake Passage transport. This is the typical conundrum: it is difficult to assess whether any of the given parameterizations "improve" the model since comparing to observational metrics may obscure compensating errors in different parameterizations. Therefore, for the purposes of this analysis, we simply investigate the sensitivity of the model to the tidal abyssal mixing parameterization. Here we present comparisons of the diagnosed stratification and vertical diffusivity, the strength and structure of the MOC, the poleward heat transport, and the ideal age tracer for the cases listed in Table 1.

Since the vertical diffusivity from the tidal parameterization is a function of the model's state, it must be diagnosed from the simulations. The horizontally averaged diffusivities are shown in Fig. 2a. It should be noted that we are only considering the contribution to the diffusivity arising from the parameterized tidal mixing; the contributions from KPP, convective mixing, and numerical mixing are excluded. We see that, as a 
TABLE 2. Summary of ocean model metrics for cases listed in Table 1 . The metrics are the volume-averaged temperature $\left[T\left({ }^{\circ} \mathrm{C}\right)\right]$; the strength of the upper limb of the MOC in the North Atlantic [NA MOC (Sv)]; the strength of the lower limb of the MOC for the global ocean [Deep MOC (Sv)]; the poleward heat transport at $25^{\circ} \mathrm{N}$ in the North Atlantic [NA PHT $25^{\circ} \mathrm{N}(\mathrm{PW})$ ]; the Drake Passage transport [Drake (Sv)]; the ideal age averaged over the volume of the North Pacific Ocean, north of $10^{\circ} \mathrm{N}$ and deeper than $2500 \mathrm{~m}$ [Pac. age (years)]; and the total power utilized in the deep ocean by the vertical mixing parameterization [Power (TW)].

\begin{tabular}{|c|c|c|c|c|c|c|c|}
\hline Case & $T\left({ }^{\circ} \mathrm{C}\right)$ & NAMOC (Sv) & Deep MOC (Sv) & NA PHT $25^{\circ} \mathrm{N}(\mathrm{PW})$ & Drake (Sv) & Pac. age (years) & Power (TW) \\
\hline A & 2.91 & 16.2 & 12.4 & 0.73 & 126 & 1885 & 1.23 \\
\hline B & 1.96 & 15.4 & 12.5 & 0.72 & 149 & 2113 & 0.95 \\
\hline $\mathrm{C}$ & 3.96 & 17.9 & 16.4 & 0.77 & 113 & 1502 & 1.63 \\
\hline $\mathrm{D}$ & 5.28 & 21.3 & 21.2 & 0.80 & 115 & 1057 & 2.46 \\
\hline $\mathrm{E}$ & 5.17 & 23.6 & 12.6 & 0.90 & 123 & 1469 & 2.33 \\
\hline $\mathrm{F}$ & 1.08 & 13.6 & 14.3 & 0.67 & 172 & 1830 & 0.55 \\
\hline $\mathrm{G}$ & 4.71 & 23.1 & 7.0 & 0.91 & 137 & 2408 & 2.39 \\
\hline $\mathrm{H}$ & 6.58 & 25.5 & 10.2 & 0.88 & 121 & 1231 & 4.20 \\
\hline I & 7.32 & 7.6 & 43.2 & 0.02 & 179 & 411 & 8.60 \\
\hline $\mathrm{J}$ & 9.08 & 8.6 & 98.1 & -0.10 & 322 & 147 & 21.18 \\
\hline K & 1.77 & 14.7 & 13.7 & 0.69 & 149 & 1964 & 0.98 \\
\hline $\mathrm{L}$ & 1.43 & 14.0 & 20.6 & 0.67 & 156 & 1750 & 0.78 \\
\hline M & 2.37 & 15.3 & 13.1 & 0.69 & 129 & 2220 & 1.34 \\
\hline $\mathrm{N}$ & 3.79 & 16.6 & 26.8 & 0.71 & 110 & 1594 & 2.20 \\
\hline $\mathrm{O}$ & 1.99 & 13.4 & 10.3 & 0.65 & 99 & 2027 & 1.04 \\
\hline$P$ & 3.37 & 24.7 & 18.7 & 1.06 & 178 & 942 & 4.83 \\
\hline $\mathrm{Q}$ & 1.43 & 12.8 & 14.3 & 0.62 & 88 & 2056 & 0.89 \\
\hline $\mathrm{R}$ & 1.01 & 13.7 & 16.1 & 0.70 & 194 & 1431 & 1.04 \\
\hline S & 2.80 & 15.3 & 6.4 & 0.68 & 118 & 2922 & 0.95 \\
\hline $\mathrm{T}$ & 1.34 & 13.9 & 25.5 & 0.67 & 156 & 1792 & 0.87 \\
\hline $\mathrm{U}$ & 1.93 & 13.4 & 14.0 & 0.69 & 173 & 1742 & 1.00 \\
\hline $\mathrm{W}$ & 1.73 & 14.7 & 13.4 & 0.69 & 151 & 1937 & 0.94 \\
\hline $\mathrm{X}$ & 1.72 & 14.7 & 13.9 & 0.69 & 152 & 1924 & 0.92 \\
\hline $\mathrm{Y}$ & 1.69 & 14.7 & 14.9 & 0.69 & 153 & 1907 & 0.90 \\
\hline $1^{\circ}$ Standard & 3.19 & 19.9 & 17.0 & 1.01 & 135 & - & 1.26 \\
\hline $1^{\circ}$ Tidal & 3.06 & 19.8 & 22.3 & 1.01 & 127 & - & 1.02 \\
\hline $1^{\circ}$ Limited & 3.06 & 19.8 & 22.7 & 1.00 & 127 & - & 1.08 \\
\hline Observations & $3.71^{\mathrm{a}}$ & $18^{\mathrm{b}}$ & $22^{\mathrm{b}}$ & $1.28^{\mathrm{c}}$ & $134^{\mathrm{d}}$ & - & $1-3^{\mathrm{e}}$ \\
\hline
\end{tabular}

${ }^{\text {a }}$ Sources for observations: Levitus et al. (1998) and Steele et al. (2001).

${ }^{\mathrm{b}}$ Source for observations: Talley et al. (2003).

${ }^{\mathrm{c}}$ Source for observations: Talley (2003).

${ }^{\mathrm{d}}$ Source for observations: Cunningham et al. (2003).

e Sources for observations: Munk and Wunsch (1998) and St. Laurent and Simmons (2006).

function of depth, the spatially averaged diffusivity is higher than the standard mixing parameterization over most of the water column, but it is substantially higher than the standard diffusivity at all depths, similar to the results of Simmons et al. (2004) and Saenko and Merryfield (2005). In certain locations this simple time average of the diffusivity may be strongly biased by a few time steps when the diffusivity is large, as the stratification goes to zero; though those moments result in large diffusivities they accomplish very little mixing of density since they are acting on no gradient. Furthermore, it should be noted that in the abyssal ocean at a given depth while the average value of $\kappa$ is large, the majority of the of $\kappa$ values are less than $1 \times 10^{-4} \mathrm{~m}^{2} \mathrm{~s}^{-1}$, and most are in the range of $0.1-0.2 \times 10^{-4} \mathrm{~m}^{2} \mathrm{~s}^{-1}$. The horizontally averaged stratification for cases A, F, H, and $\mathrm{K}$ are plotted in Fig. $2 \mathrm{~b}$ and show that, despite having substantially higher diffusivities in the tidal mixing case, the averaged stratification is higher over most of the water column (between 500 and $3000 \mathrm{~m}$ ). Another way to examine the mixing rates in the model is to plot the depth profile of the horizontally averaged potential energy created by the vertical mixing $\left(\rho \kappa_{\nu} N^{2}\right)$, which is shown in Fig. 2c. The standard run with the specified mixing profile shows a distinct (and likely unphysical) peak around $1000 \mathrm{~m}$, where the mixing profile has its transition region. The energy generation profile for tidal mixing case shows a steady decline into the deep ocean.

The Atlantic Ocean and global ocean integral MOCs are shown in Figs. 3 and 4 for the low-resolution simulations for cases A, F, H, and $\mathrm{K}$. The differences between the MOCs for the traditional mixing parameterization and the tidal mixing parameterization are relatively 

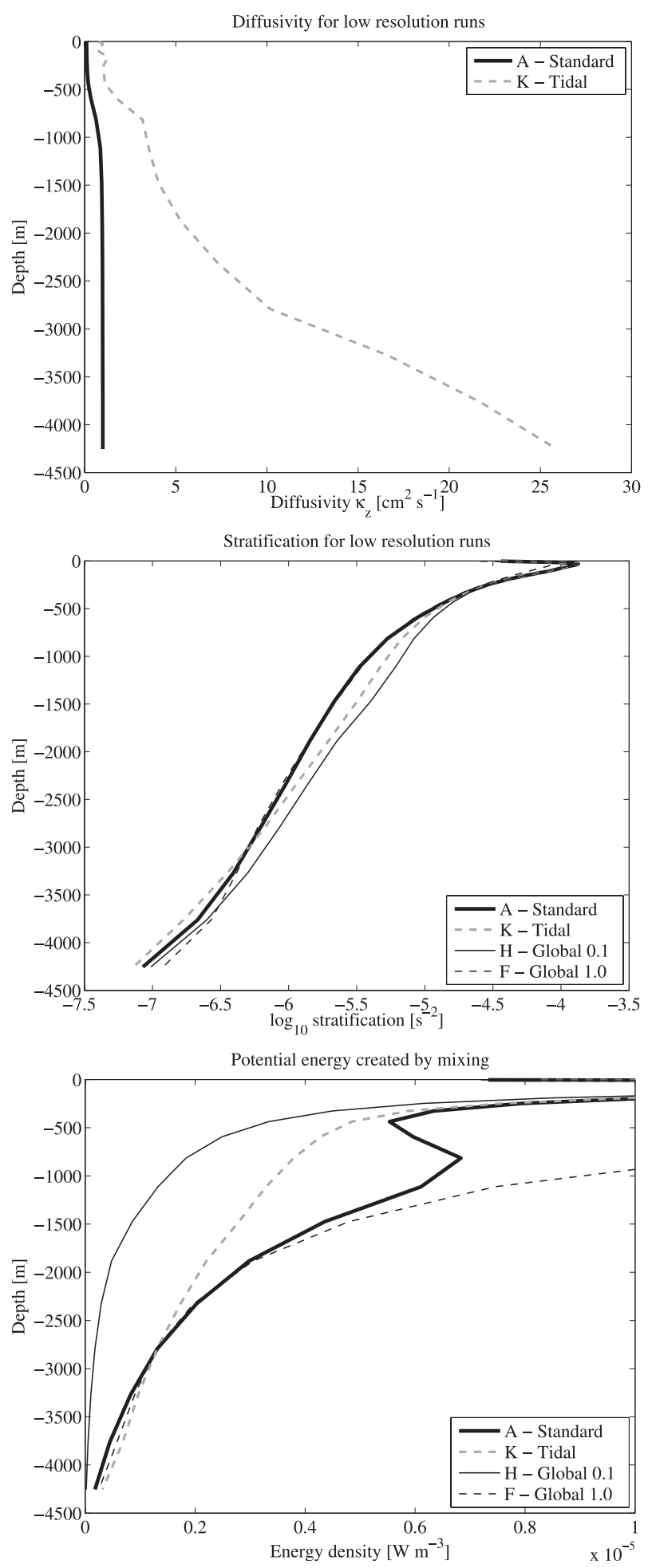

FIG. 2. (a) Horizontal-average vertical diffusivity for case A (control: std vertical mixing) and case $\mathrm{K}$ (tidal parameterization). (b) Horizontal-average buoyancy frequency for case A, case $\mathrm{K}$, case $\mathrm{H}$ (global $\kappa_{\nu}=0.1 \times 10^{-4} \mathrm{~m}^{2} \mathrm{~s}^{-1}$ ), and case $\mathrm{F}\left(\right.$ global $\kappa_{\nu}=1.0 \times$ $10^{-4} \mathrm{~m}^{2} \mathrm{~s}^{-1}$ ). (c) Horizontal-average gravitational potential energy generation by the vertical mixing for cases $\mathrm{A}, \mathrm{K}, \mathrm{H}$, and $\mathrm{F}$. modest. The strength of the upper limb of the MOC in the North Atlantic was $16.2 \mathrm{~Sv}\left(1 \mathrm{~Sv} \equiv 10^{6} \mathrm{~m}^{3} \mathrm{~s}^{-1}\right)$ in the control run compared to a slightly weaker value of $14.7 \mathrm{~Sv}$ in the case with tidal mixing. These can be compared to two other cases, one with a constant value of $0.1 \times 10^{-4} \mathrm{~m}^{2} \mathrm{~s}^{-1}$ (case $\mathrm{F}$ ) and the other with $1.0 \times 10^{-4} \mathrm{~m}^{2} \mathrm{~s}^{-1}$ (case $\left.\mathrm{H}\right)$, which had MOC strengths of 13.6 and $25.5 \mathrm{~Sv}$, respectively. Other cases not plotted are summarized in Table 2. The strength of the lower limb of the globally integrated MOC was somewhat stronger using the new parameterization, changing from 12.4 $\mathrm{Sv}$ for the standard case to $13.7 \mathrm{~Sv}$ for the tidal mixing case. For the other two cases shown, the strength of the lower limb was $14.3 \mathrm{~Sv}$ for the constant value of $0.1 \times 10^{-4} \mathrm{~m}^{2} \mathrm{~s}^{-1}$ (case F) and somewhat weaker with $10.3 \mathrm{~Sv}$ for the case with a constant $1.0 \times 10^{-4} \mathrm{~m}^{2} \mathrm{~s}^{-1}$ (case H). Overall it appears that switching to the tidal mixing parameterization slightly increases the strength of the deep MOC and modestly decreases the upper limb of the MOC compared to the standard mixing case.

Perhaps the most important ocean metric for climate models is the global ocean's poleward heat transport, and in this suite of model runs it is surprisingly insensitive to the abyssal mixing parameterization. Examining the poleward heat transport shown in Fig. 5, and the heat transport at $25^{\circ} \mathrm{N}$ tabulated in Table 2 demonstrates that there is little difference between the control case (case a) and the case with the tidal parameterization (case $\mathrm{K}$ ), indicating that the deep-ocean mixing in the model is not a strong control on the poleward heat transport. Other cases, such as the Bryan and Lewis (1979) (case E), show larger differences in the heat transport, and in particular the case with a global value of $1.0 \times 10^{-4} \mathrm{~m}^{2} \mathrm{~s}^{-1}$ (case $\mathrm{H}$ ) shows large deviations, indicating that changing the mixing in the upper ocean has much larger effects on the meridional overturning circulation and heat transport than changing the mixing in the deep ocean. Indeed, so long as the mixing in the thermocline is small (order $0.1 \times 10^{-4} \mathrm{~m}^{2} \mathrm{~s}^{-1}$ ), any parameterization of the mixing in the deep ocean may give indistinguishable results, at least within the uncertainties in the observational data.

The total power $P$ consumed by the tidal mixing scheme in the conversion from turbulent kinetic energy into potential energy is

$$
P=\frac{1}{\Gamma} \int \rho N^{2} \kappa_{\nu} d V
$$

which, for the case of the tidal parameterization using Eq. (2), is 

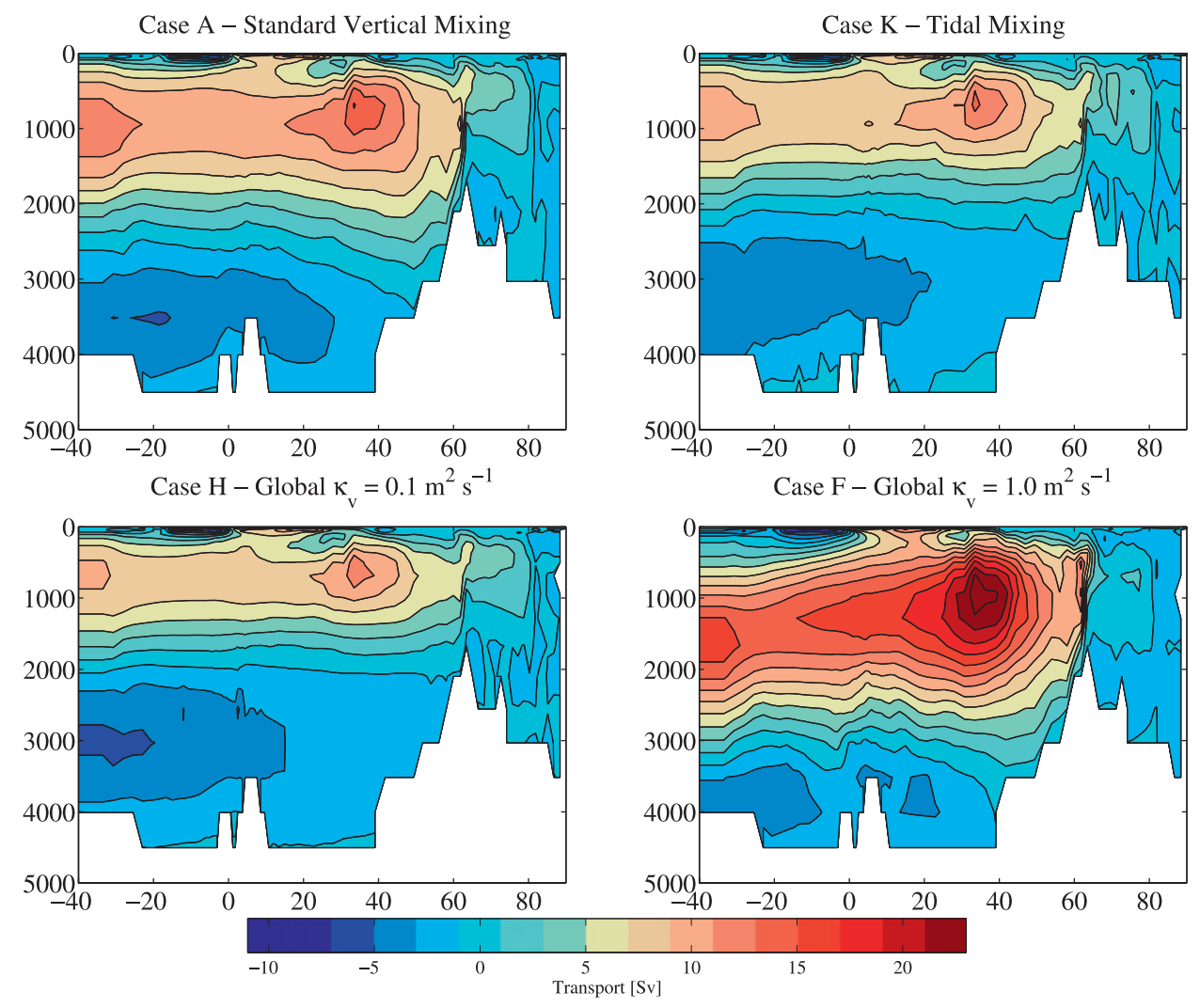

FIG. 3. Atlantic Ocean meridional overturning streamfunction for case A (control: std vertical mixing), case K (tidal parameterization), case $\mathrm{H}\left(\right.$ global $\kappa_{\nu}=0.1 \times 10^{-4} \mathrm{~m}^{2} \mathrm{~s}^{-1}$ ), and case $\mathrm{F}\left(\right.$ global $\kappa_{\nu}=1.0 \times 10^{-4} \mathrm{~m}^{2} \mathrm{~s}^{-1}$ ).

$$
P=\frac{0.1}{\Gamma} \int \rho(x, y, z) N^{2}(x, y, z) d V+q \int E(x, y) F(z) d V
$$

Therefore, the interpretation of the power consumption is subject to assumptions about $q$ and $\Gamma$ separately. For the purposes here of diagnosing the total energy utilized by the parameterization, we choose to assume that $\Gamma$ was held constant, while $q$ was varied from 0.1666 to 1.666. An alternative way to consider this would be to merely scale the energy flux $E(x, y)$ by a constant, since that would have the same effect. The power consumed by the vertical mixing parameterization in tabulated in Table 2. For the standard tidal mixing (case A), the parameterization uses $1.27 \mathrm{TW}$ of mechanical energy, compared to $1.01 \mathrm{TW}$ for the tidal mixing parameterization (case K), $0.58 \mathrm{TW}$ for the global $\kappa_{\nu}$ $=0.1 \times 10^{-4} \mathrm{~m}^{2} \mathrm{~s}^{-1}$ (case $\left.\mathrm{F}\right)$, a rather large value of $4.23 \mathrm{TW}$ for the global $\kappa_{\nu}=1.0 \times 10^{-4} \mathrm{~m}^{2} \mathrm{~s}^{-1}$ (case $\mathrm{H}$ ), and 2.36 TW for the Bryan and Lewis (1979) parameterization (case E). The assumed value for the power consumed by abyssal mixing is about $1 \mathrm{TW}$ (Munk and Wunsch 1998), though it may be substan- tially higher in the range of 2-3 TW (St. Laurent and Simmons 2006).

The two parameters $q$ and $\Gamma$ are each uncertain (and likely should be functions of space and time), but since they appear together in the parameterization we can consider the effects of changing them together (cases L, $\mathrm{M}$, and N). Figure 6 shows the difference in the poleward heat transport between the standard case (case A) and the tidal mixing case (case $\mathrm{K}$ ) and for the series of runs in which the fraction of the internal wave flux that is dissipated locally $q$ is varied between $q=0$ (case $\mathrm{H}$ ), $q=1 / 6($ case $\mathrm{L}), q=2 / 3$ (case $\mathrm{M})$, and $q=5 / 3($ case $\mathrm{N})$. While it is energetically inconsistent to set $q>1$, varying $q$ is the same as changing $\Gamma$; therefore, these runs are equivalent to varying their product $(q \Gamma)$ from its nominal value of 0.066 over the range $0.033-0.33$, or varying $\Gamma$ over the range of $0-1$, the only difference is in the interpretation of the power consumption. An alternative viewpoint is that increasing $q$ is the same as simply scaling up the mixing energy source for stronger tides. Here we assume $\Gamma$ was held fixed at 0.2 ; so, while the implied power used for mixing in the deep ocean varies considerably over these runs, the poleward heat transport is largely 

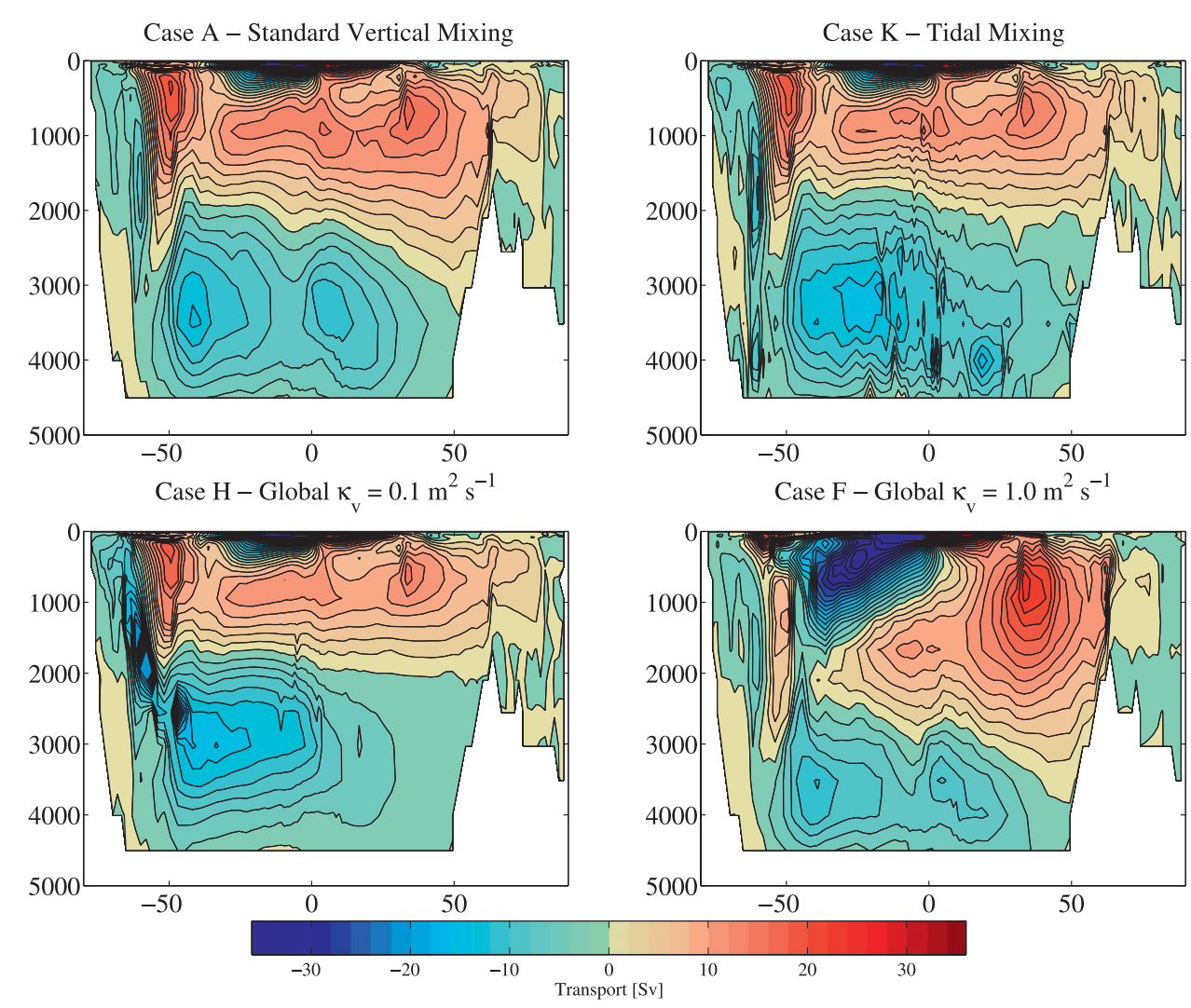

FIG. 4. Global ocean meridional overturning streamfunction for case A (control: std vertical mixing), case K (tidal parameterization), case $\mathrm{H}$ (global $\kappa_{\nu}=0.1 \times 10^{-4} \mathrm{~m}^{2} \mathrm{~s}^{-1}$ ), and case $\mathrm{F}\left(\mathrm{global} \kappa_{\nu}=1.0 \times 10^{-4} \mathrm{~m}^{2} \mathrm{~s}^{-1}\right.$ ).

unchanged. The only notable trend is that, as $q$ is increased, the southward transport of heat in the Southern Hemisphere is slightly increased (except in case $\mathrm{N}$, where it is noticeably increased).

The power needed for the vertical mixing in the model can be compared to some of the measures of the model's circulation. For runs with only changes to the vertical diffusivity in the deep ocean (all the runs with $\kappa_{\nu}=0.1 \times 10^{-4} \mathrm{~m}^{2} \mathrm{~s}^{-1}$ in the upper ocean), the strength of the upper limb of the Atlantic MOC covaries with the power consumed by the mixing (Fig. 7a), where as the deep limb of the MOC does not (Fig. 7b). Furthermore, there is a relationship between the mean transport through the Drake Passage and the power dissipation in the abyssal ocean (Fig. 8b). Saenko and Merryfield (2005) observed a similar sensitivity in their model. They attributed the increase in the Antarctic Circumpolar Current (ACC) transport to a deepening of the current by the increased vertical mixing, resulting in a stronger topographic interaction. Our suite of runs suggests a different explanation, namely that the strength of the ACC is related to the strength of the abyssal circulation. This can be explained by the mechanism pro- posed by Gent et al. (2001) whereby the strength of the ACC is strongly related to the magnitude of the southward transport in the intermediate layer of the ocean at the latitude of the Drake Passage. Gent et al. (2001) suggested that the meridional Ekman transport drives about $100 \mathrm{~Sv}$ of the Drake transport and the global thermohaline circulation drives approximately $30 \mathrm{~Sv}$. It is the latter $30 \mathrm{~Sv}$ that we concerned with here, and we find the same general result; the strength of part of the Drake Passage transport is controlled by southward flow at $61.5^{\circ} \mathrm{S}$, as is shown in Fig. 8a. Since the flow in the intermediate layer is part of the MOC whose strength is set by the abyssal mixing in the model, this results in a clear relationship between the mixing and Drake Passage transport. The strongest relationship stands out between the global integral of the abyssal power dissipation and the Drake Passage transport (Fig. 8b).

An additional indication of the model's sensitivity is the ideal age tracer (England 1995). It is an inherently integrative measure of the model's circulation. Horizontal maps of the age distribution at $2500 \mathrm{~m}$ are shown in Fig. 9 and the basin average for the abyssal North Pacific (below $2000 \mathrm{~m}$ and north of $10^{\circ} \mathrm{N}$ ) of the ideal 

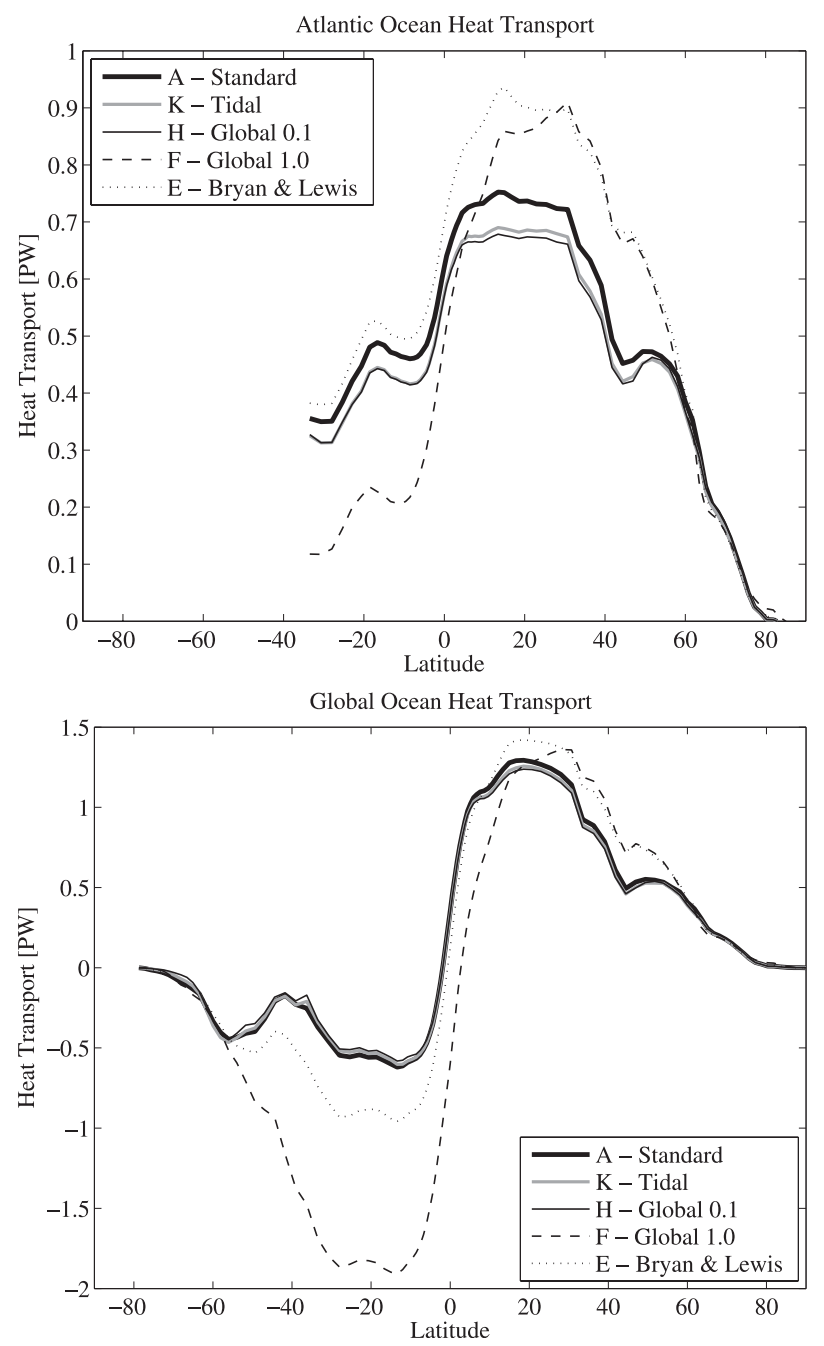

FIG. 5. Northward heat transport for case A (control: std vertical mixing), case $\mathrm{K}$ (tidal parameterization), case $\mathrm{H}$ (global $\kappa_{\nu}$ $\left.=0.1 \times 10^{-4} \mathrm{~m}^{2} \mathrm{~s}^{-1}\right)$, case F $\left(\right.$ global $\left.\kappa_{\nu}=1.0 \times 10^{-4} \mathrm{~m}^{2} \mathrm{~s}^{-1}\right)$, and case E (Bryan and Lewis 1979 parameterization).

age are listed in Table 2. It can be seen that the tidal mixing parameterization results in older ages for most of the deep ocean, in particular the North Pacific. This result is somewhat counterintuitive since the deep MOC is stronger with the tidal mixing parameterization, suggesting that ventilation rate of the deep ocean would be higher. However, it may be that the majority of the deep ocean is less ventilated because upwelling is largely confined to isolated areas of high diffusivity near rough topography.

\section{b. Medium-resolution runs}

The three $1^{\circ}$ resolution simulations show very similar results to the $3^{\circ}$ simulations. Overall, in the medium-

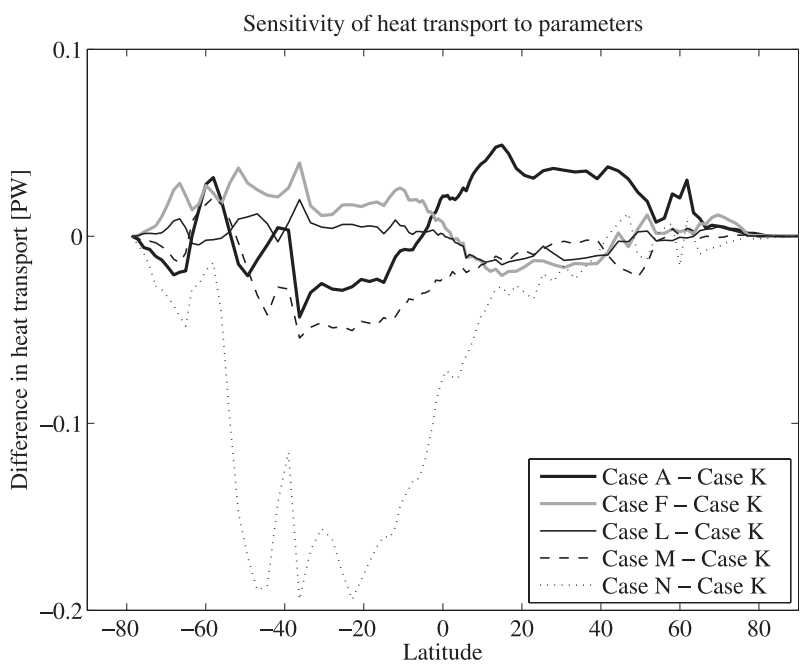

FIG. 6. Difference in the northward heat transport between case A (control: std vertical mixing) and case $\mathrm{K}$ (tidal parameterization), between case $\mathrm{H}$ (global $\kappa_{\nu}=0.1 \times 10^{-4} \mathrm{~m}^{2} \mathrm{~s}^{-1}$, equivalent to $q=0)$ and case $\mathrm{K}$, between case $\mathrm{L}(q=1 / 6)$ and case $\mathrm{K}$, between case $\mathrm{M}(q=2 / 3)$ and case $\mathrm{K}$, and between case $\mathrm{N}(q=5 / 3)$ and case $\mathrm{K}$.

resolution runs both limbs of the MOC are stronger compared to the lower-resolution runs, with the standard mixing case having $19.9 \mathrm{~Sv}$ of overturning in the upper limb of the MOC in the North Atlantic and the simulation utilizing the tidal parameterization showing a slightly weaker MOC that is $0.05 \mathrm{~Sv}$ smaller (Fig. 10). The case with the tidal parameterization does show a much stronger deep cell of the MOC compared to the standard case with the tidal case carrying $22.3 \mathrm{~Sv}$ in the deep cell compared to $17 \mathrm{~Sv}$ for the standard case (Fig. 11). This is consistent with the lower-resolution simulations.

In the medium-resolution model, the poleward transport of heat seems to be largely unaffected by the choice of the vertical mixing parameterization (Fig. 12), similar to the low-resolution model. Although the higherresolution model was only run for $500 \mathrm{yr}$ and was not in equilibrium, compared to $5000 \mathrm{yr}$ for the low-resolution model, this does not appear to be a factor. In the lowresolution model the differences in the heat transport between the standard mixing case and tidal mixing case (seen in Figs. 5 and 6) are well established by $500 \mathrm{yr}$.

There appears to be a slowly growing instability in the medium-resolution model with the tidal mixing parameterization. At the midlevel depths of the ocean, around $2500 \mathrm{~m}$, it is apparent there is a region of low stratification, which, because of the inverse relations between $\kappa_{\nu}$ and the stratification, leads to a diffusivity peak there (Fig. 13). This feedback was not evident in any of the low-resolution simulations. However, in the 

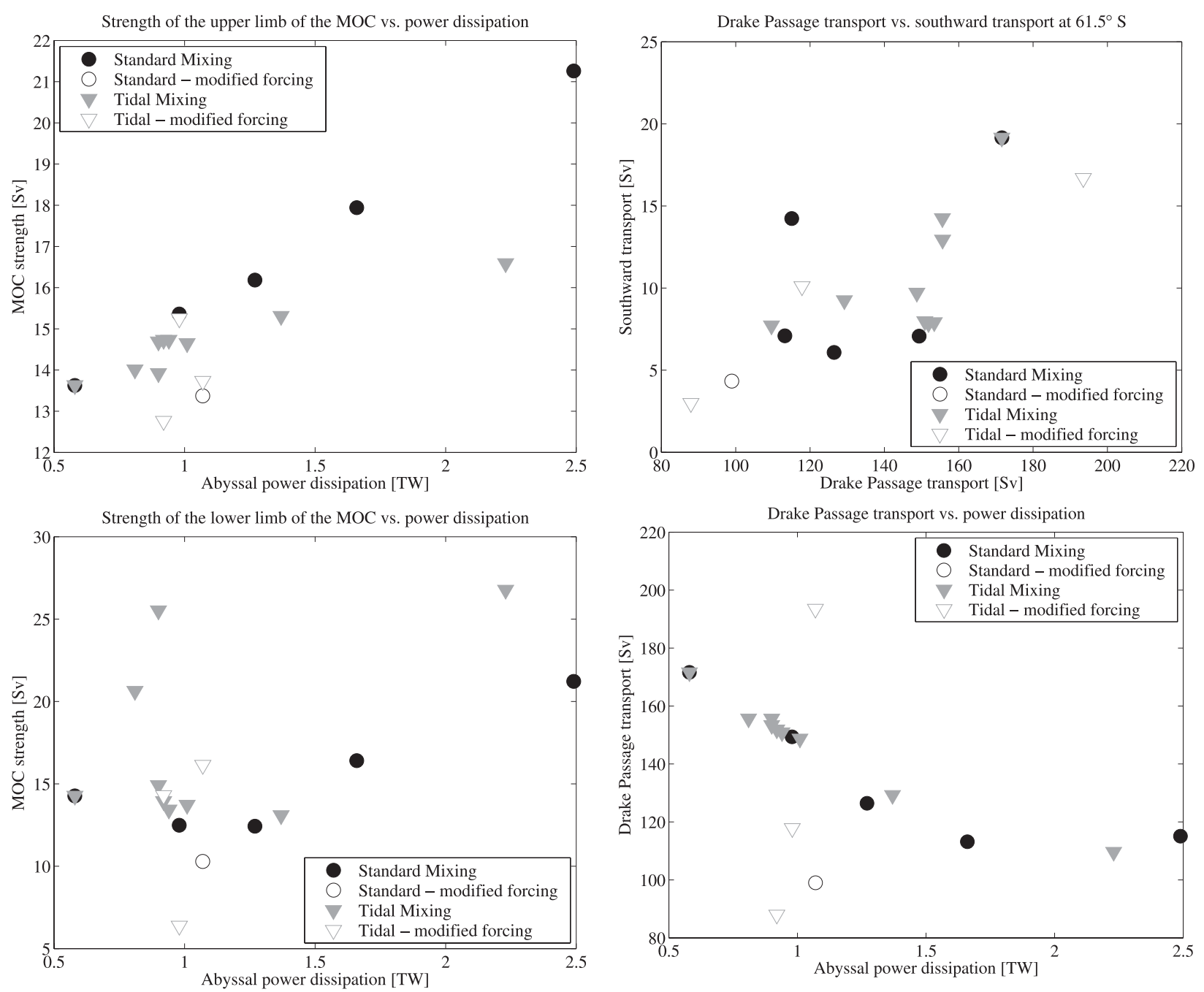

FIG. 7. Overturning strength for the upper limb of the Atlantic MOC and the lower limb of the global MOC for various mixing cases (only for cases in which the value of the diffusivity was $\kappa_{\nu}=$ $0.1 \times 10^{-4} \mathrm{~m}^{2} \mathrm{~s}^{-1}$ in the upper ocean). Cases with the standard forcing and physics are in solid symbols; cases in which the surface forcing was modified are in open symbols.

$1^{\circ}$ model with the limit on $\kappa_{\nu}$ of $1000 \times 10^{-4} \mathrm{~m}^{2} \mathrm{~s}^{-1}$, the diffusivity peak develops slowly in time. It is evident in the simulations by year 200 of the simulation. The low diffusivity layer does not appear in the Southern Ocean (south of $30^{\circ} \mathrm{S}$ ). In the Arctic Ocean, the low stratification layer quickly develops in the first $100 \mathrm{yr}$ of the simulation and slowly deepens over the course of the run. In the Arctic Ocean, at least, this leads to a more realistic stratification in the deep basins there.

It is conjectured that this is the result of a feedback between the mixing parameterization and the stratification, and it is possible that it might be prevented by lowering the upper limit on the vertical mixing. It was for this reason that the third run was performed with a

FIG. 8. (a) Drake Passage transport versus the subthermocline southward transport at $61.5^{\circ} \mathrm{S}$, as in Gent et al. (2001), and (b) the global integral of abyssal power dissipation versus Drake Passage transport.

limit on $\kappa_{\nu}$ of $100 \times 10^{-4} \mathrm{~m}^{2} \mathrm{~s}^{-1}$. In the low-resolution model, limiting $\kappa_{\nu}$ makes only modest changes to the model state (see cases $\mathrm{W}, \mathrm{X}$, and $\mathrm{Y}$ in Table 2), except when $\kappa_{\nu}$ is limited to $20 \times 10^{-4} \mathrm{~m}^{2} \mathrm{~s}^{-1}$ (as in Saenko and Merryfield 2005) - then more significant changes are seen in the MOC, and power used by mixing is reduced by about $10 \%$. In the medium-resolution model, capping $\kappa_{\nu}$ does significantly reduce the magnitude of the diffusivity peak (Fig. 13), but it does not entirely remove it. Despite this peak in the diffusivity, there is no extra potential energy generation there, a further indication that it arises because the stratification becomes weak at those depths (Fig. 13). In the new standard version of CCSM ocean model, the diffusivity is capped at $100 \times$ $10^{-4} \mathrm{~m}^{2} \mathrm{~s}^{-1}$ (along with higher vertical resolution and 
Case A - Standard Vertical Mixing

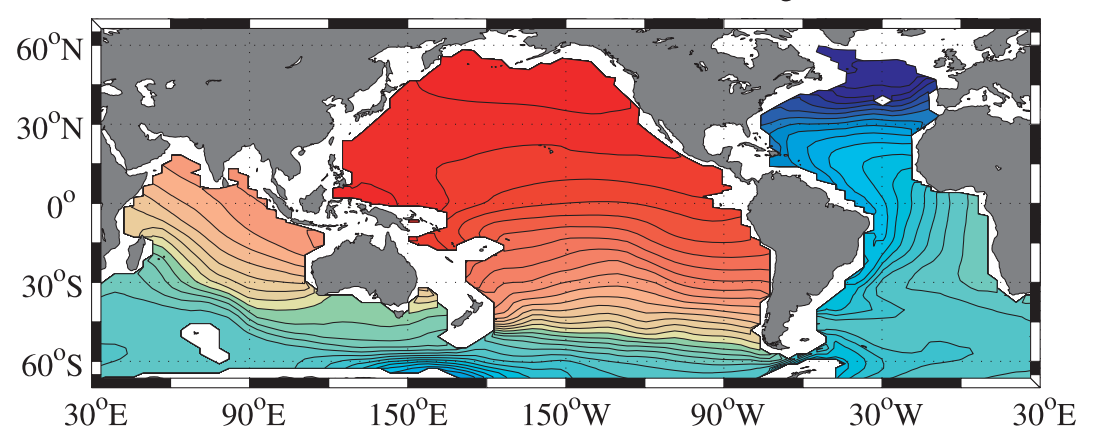

Case K - Tidal Mixing

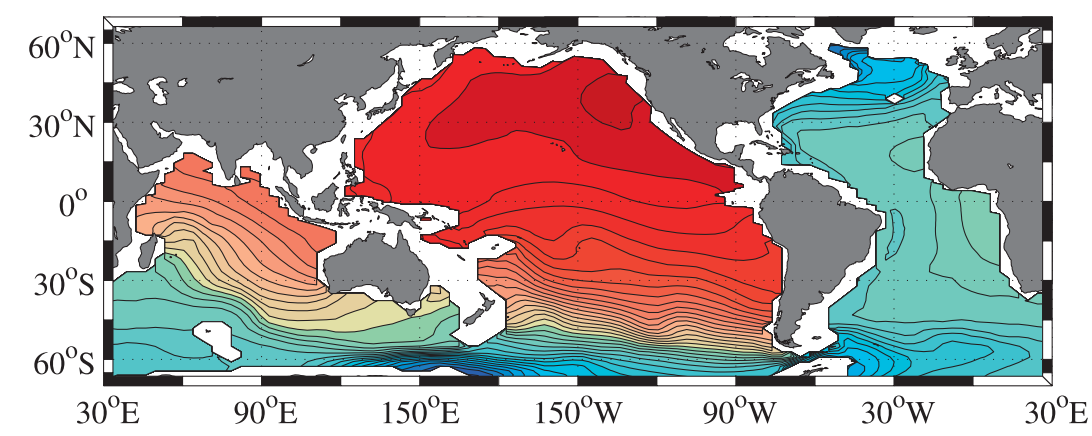

Case $\mathrm{H}-$ Global $\kappa_{\mathrm{v}}=0.1 \mathrm{~m}^{2} \mathrm{~s}^{-1}$

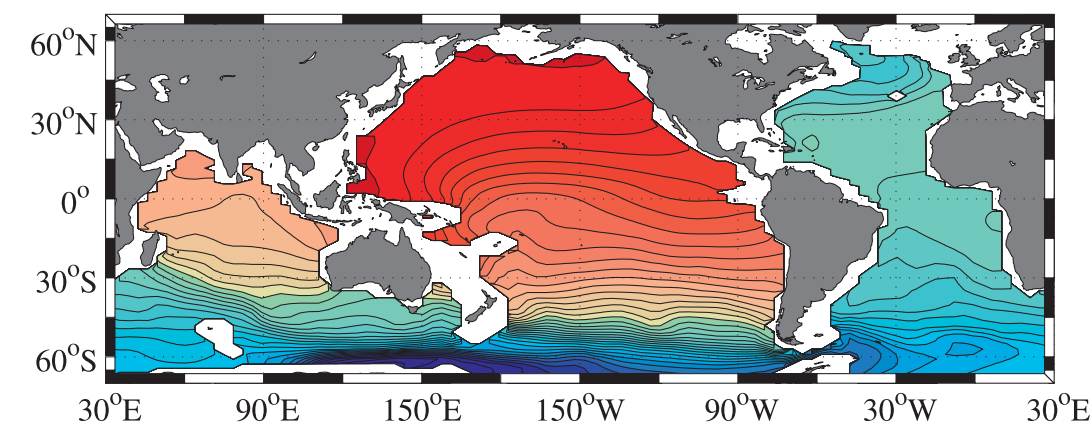

Case F - Global $\kappa_{\mathrm{v}}=1.0 \mathrm{~m}^{2} \mathrm{~s}^{-1}$
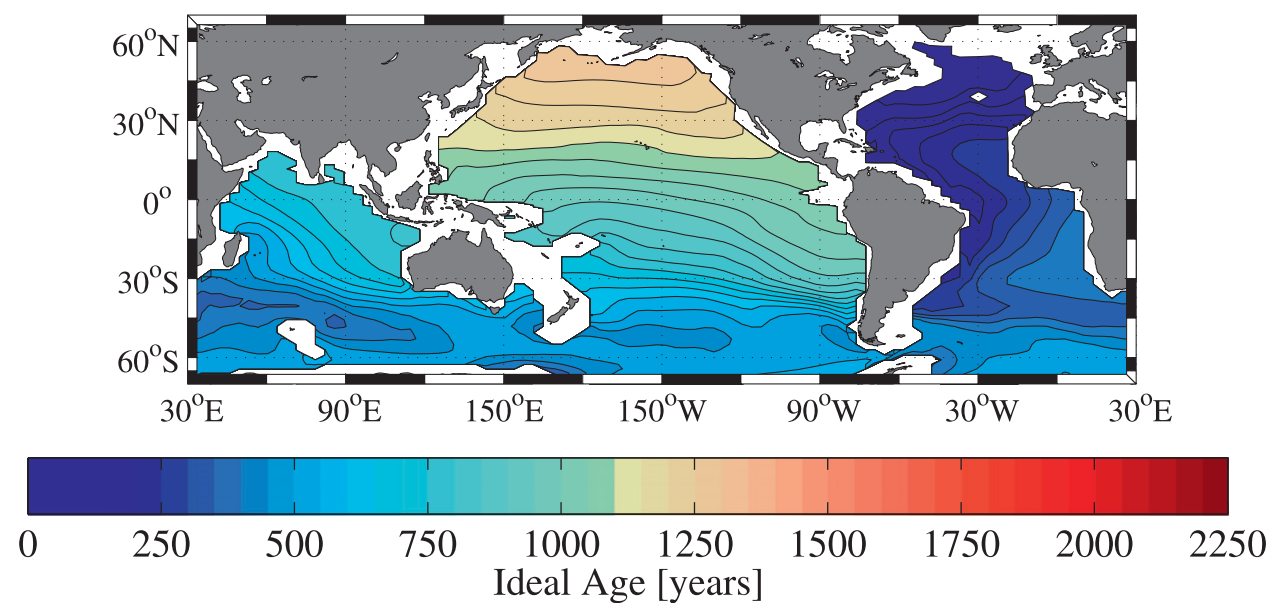

FIG. 9. Ideal age at $2500 \mathrm{~m}$ for A (control: std vertical mixing), case $\mathrm{K}$ (tidal parameterization), case $\mathrm{H}$ $\left(\right.$ global $\left.\kappa_{\nu}=0.1 \times 10^{-4} \mathrm{~m}^{2} \mathrm{~s}^{-1}\right)$, and case F (global $\left.\kappa_{\nu}=1.0 \times 10^{-4} \mathrm{~m}^{2} \mathrm{~s}^{-1}\right)$. 


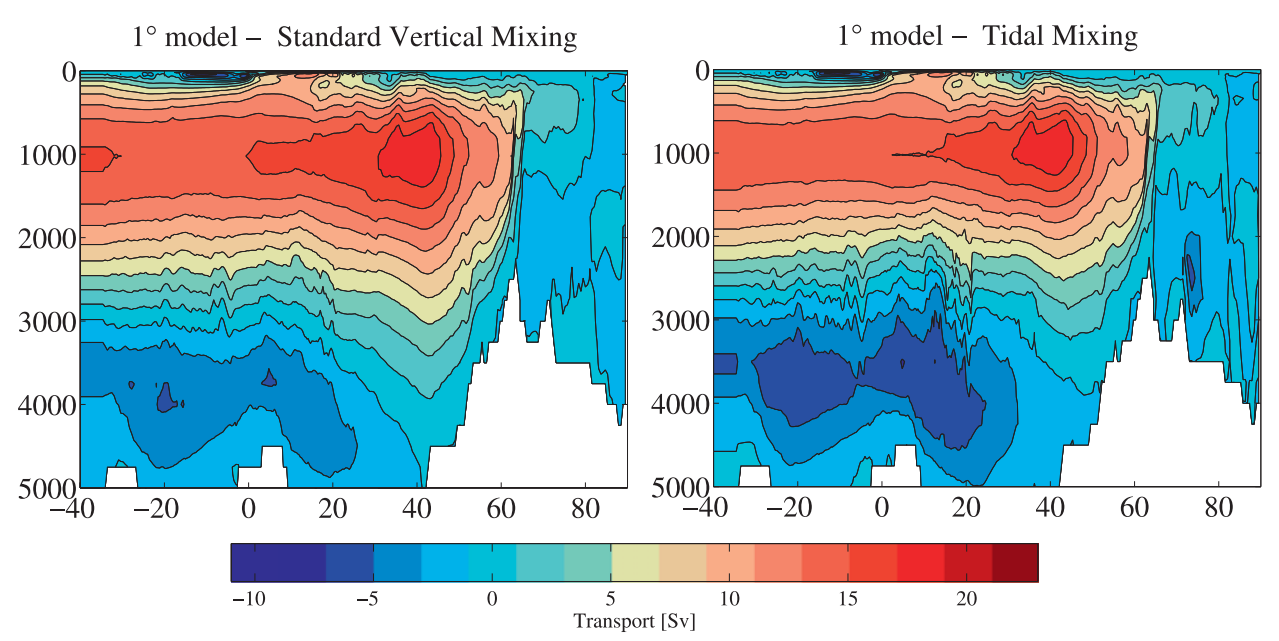

FIG. 10. Atlantic Ocean meridional overturning streamfunction for the medium-resolution $\left(\approx 1^{\circ}\right)$ control case and the case with the tidal parameterization.

additional physics changes to the core model), and in the simulations performed so far the diffusivity peak has not appeared (results not shown).

\section{Discussion and conclusions}

The overall conclusion of this study is that the transition from the Bryan and Lewis (1979)-type vertical mixing scheme to a parameterization based on the energetics of tidally generated internal waves has a noticeable impact on the MOC in an OGCM. However, the poleward ocean heat transport does not appear to be strongly affected by the mixing in the abyssal ocean, as it only appears to scale with the value of the mixing in the upper ocean and thermocline. Nevertheless, there are still some changes to the modeled ocean state depending on which parameterization is used for the vertical mixing in the deep ocean.

The tidal mixing parameterization strengthens the deep cell of the MOC compared to the standard ad hoc specified vertical profile. While the strong dependence of the strength of the MOC and poleward heat transport on the vertical diffusivity that was seen by Bryan (1987) is generally confirmed, it is only true for the set of experiments in which $\kappa_{\nu}$ is spatially constant over the whole water column. For those experiments in which the upper-ocean value was set to be a small constant, $\kappa_{\nu}=0.1 \times 10^{-4} \mathrm{~m}^{2} \mathrm{~s}^{-1}$, the scaling is not applicable and is not followed for the tidal mixing cases either (for which upper-ocean $\kappa_{\nu}=0.1 \times 10^{-4} \mathrm{~m}^{2} \mathrm{~s}^{-1}$ as well). Overall, the poleward heat transport seems to be a very weak function of the abyssal mixing parameterization as long as the diffusivity is low in the thermocline.
The relative insensitivity of the heat transport to the specification of the abyssal mixing may result from our use of a surface flux forcing diagnosed from an atmospheric state that does not respond to changes in the ocean. Hence it appears to the ocean as though the atmosphere has an infinite heat capacity and the surface flux forces the ocean to transport the required amount of heat implied by the atmospheric analysis despite changes in the ocean circulation. However, in the lowresolution model cases where the upper-ocean vertical mixing was changed, the ocean's poleward heat transport was significantly altered; therefore, it is not completely dictated by the surface flux forcing. In either case, in a fully coupled climate model where there can be atmosphere-ocean feedbacks, the specification of the abyssal vertical mixing might have a larger impact on the ocean's poleward heat transport, and this should be investigated further in future work.

In the low-resolution model, there appears to be a direct relationship between the amount of power required by the mixing parameterization in the deep ocean and the strength of the upper limb of the MOC in the North Atlantic, consistent with at least some portion of the MOC being driven by mechanical mixing. However, there is no apparent relationship between the strength of the lower limb of the global ocean's MOC and the power dissipation. Furthermore, there appears to be a relationship between the power dissipation and the Drake Passage transport. This can be partially explained by the mechanism proposed by Gent et al. (2001) in which the southward transport of intermediate water at the latitude of the Drake Passage sets the eastward transport of the ACC through the Drake 


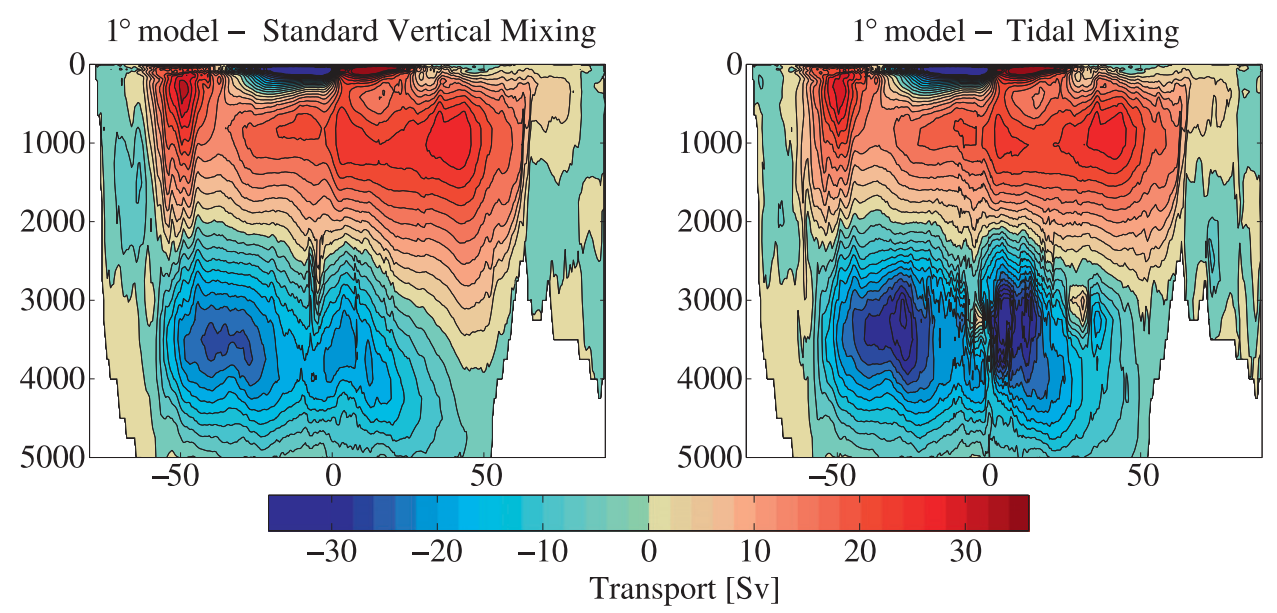

FIG. 11. Global ocean meridional overturning streamfunction for the medium-resolution $\left(\approx 1^{\circ}\right)$ control case and the case with the tidal parameterization.

Passage. Our results suggest that this explanation may need further refinement, since the ACC transport seems to be a stronger function of the abyssal power dissipation than of the southward transport at Drake Passage.

The model is clearly very sensitive to the value of mixing in the thermocline; however, since most OGCMs already use a low value for mixing in the thermocline, the impact of switching to the parameterization of St. Laurent et al. (2002) will likely result in modest changes in the model's simulated climate. The tidal mixing parameterization is preferable as it is based on energy conservation and is more consistent with physical principles. Furthermore, it is important to note that using the tidal mixing parameterization results in an ocean model that is energetically consistent with the known energy constraints on the ocean's energy budget.

It is expected that the parameterization reproduces the gross dynamical picture of mixing in the deep ocean; however, there are still many details yet to be filled in. For example, the parameters that are currently specified as constants are likely spatially or even temporally variable. More work to understand how the fraction of the internal wave flux that is dissipated locally $q$ and the vertical decay scale of the turbulence $\zeta$ are related to the roughness, length scales, and type of topography is needed. The mixing efficiency $\Gamma$ may be a function of the local state variables as well (Arneborg 2002; Peltier and Caulfield 2003); however, experimental and observational data are needed to elucidate this. Additionally, the background mixing $\kappa_{0}$ may need to be made a function of space to account for such things as parametric subharmonic instability (PSI) at critical latitudes (MacKinnon and Winter 2005; Alford et al. 2007) and other changes in the distribution of wave energy and dissipation (Gregg et al. 2003; Hibiya et al. 2006; Jochum 2009).

As was noted in the introduction, the mixing in the model is controlled by several parameterizations: the mixed layer (KPP; Large et al. 1994), convective mixing, the eddy mixing parameterization (Gent and McWilliams 1990), etc. These combine to govern the overall diffusive flux of tracers in the model. Ultimately, the component of the mixing discussed here is only a small portion of the ocean mixing (about a sixth in the enhanced mixing portion over rough topography, and roughly a third in the background $0.1 \times 10^{-4} \mathrm{~m}^{2} \mathrm{~s}^{-1}$ portion), leaving about a half to be input by the wind (Munk and Wunsch 1998). St. Laurent and Simmons (2006) suggest that the power consumed by mixing in the deep ocean may be even larger (2-3 TW) based on estimated diffusivities. It is unclear at this time where this power would be supplied from. Although there is still enough uncertainty in the tidal-driven component to accommodate some of this (i.e., in the parameters $\Gamma$ and $q$ ), perhaps there is an additional source from the generation of internal lee waves resulting from the interaction of mesoscale eddies with rough topography (Gille et al. 2000; Naveira Garabato et al. 2004; Kunze et al. 2006; Naveira Garabato et al. 2007) and flows over sills Thurnherr et al. (2005); MacKinnon et al. (2008). Additional mixing comes from the energy input by the wind generating near-inertial waves (Munk and Wunsch 1998; Alford 2001; von Storch et al. 2007), but exactly how much of this makes it into the deep ocean is unclear. In future models, it may be necessary to have an embedded internal wave model within the OGCM that includes the generation of internal wave energy from the wind and tides, wave-wave interactions, PSI, their energy propagation, their interaction with topography, 


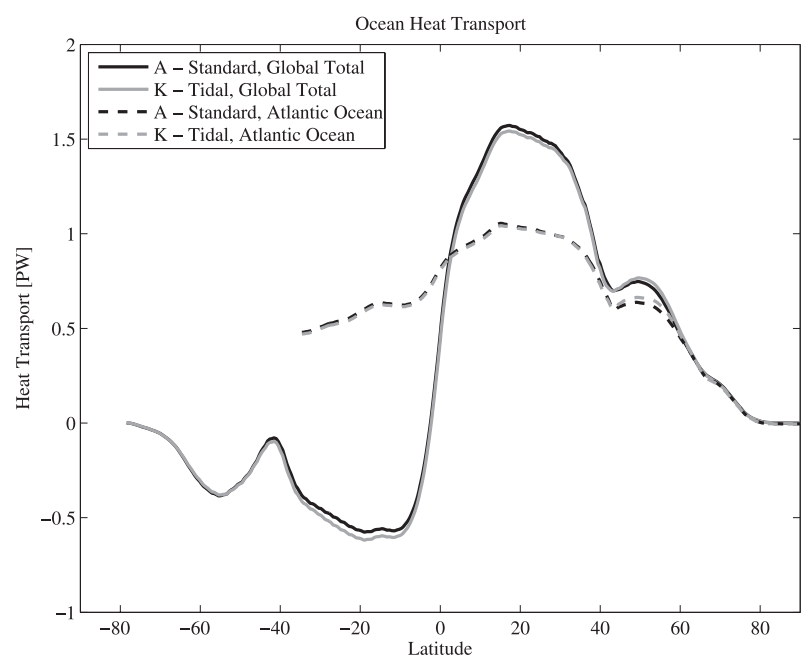

FIG. 12. Northward heat transport for the medium-resolution $\left(\approx 1^{\circ}\right)$ control case and the case with the tidal parameterization.

and their dissipation to fully understand the diffusivity in the ocean. Strides need to be made in understanding both the background interior mixing and the upperocean wind-driven mixing.

Given the results of these experiments, mixing in the upper ocean has a much more significant impact on the horizontal circulation, the meridional overturning circulation, and poleward heat transport than does the abyssal mixing. While this paper focused on these particular metrics, the impact of the mixing scheme on the transport of freshwater, nutrients, chlorofluorocarbon, and other important climate-relevant tracers such as carbon dioxide still needs to be explored. There are also still questions regarding the numerical methods used to implement this parameterization, since its combination with bottom boundary layer transport schemes is difficult. The mixing parameterization creates enhanced mixing near the bottom, but generally climate models are overly diffuse in their dense overflow waters, which the boundary layer schemes are meant to overcome. Additionally, the tidal velocities should be considered in the bottom boundary layer turbulence (Canuto et al. 2008, manuscript submitted to Ocean Modell.), which has been neglected here. Finally, experiments with this parameterization should be repeated with layer ocean models in which the implicit vertical mixing is smaller and more controllable.

In another context, the tidal mixing parameterization has been used in the paleoclimate eras to study the effect of lowered sea level during the Last Glacial Maximum (LGM; Montenegro et al. 2007). During the LGM sea level was approximately $125 \mathrm{~m}$ lower than in the present day because water was locked up in the large
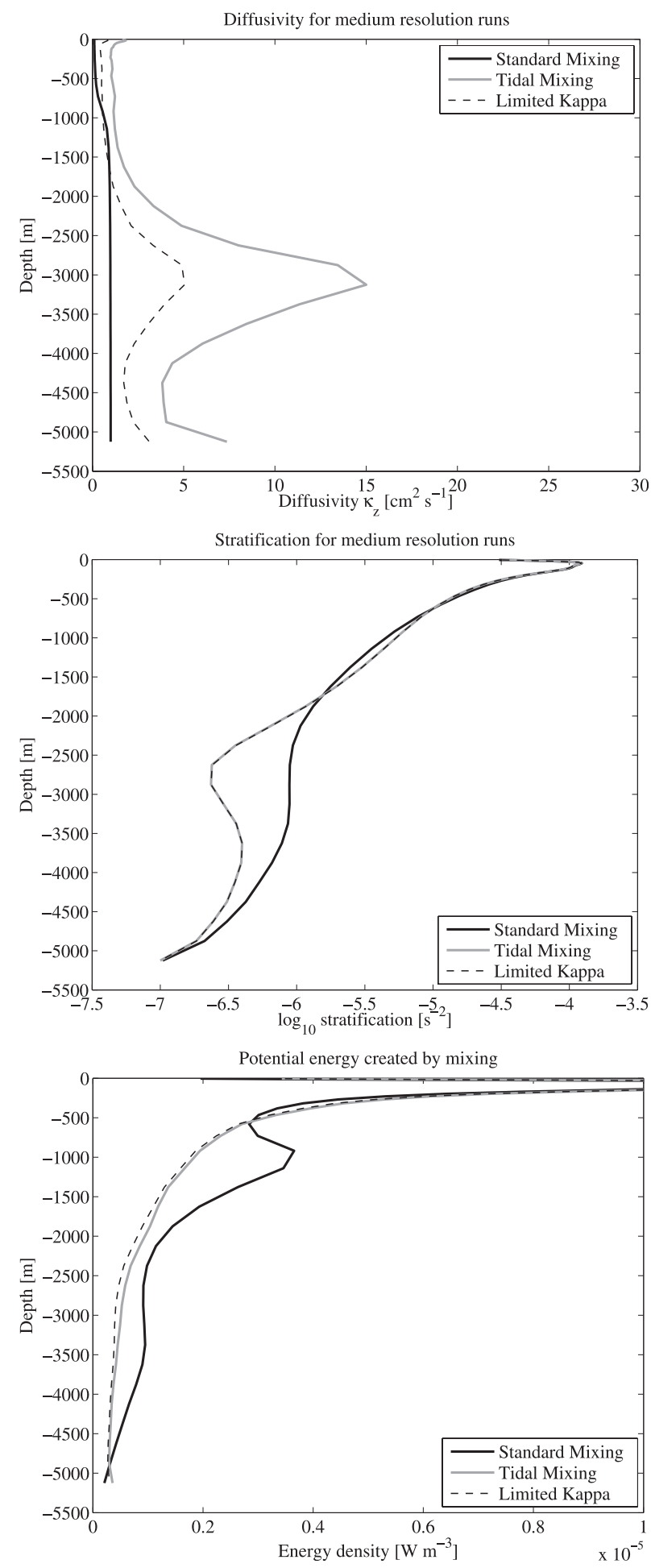

FIG. 13. Horizontal-average vertical diffusivity, horizontalaverage stratification, and horizontal-averaged gravitational potential energy generation by the vertical mixing as functions of depth for medium-resolution runs. 
glacial ice sheets. The lowering of the sea level dried much of the shallow coastal seas where presently a large portion of the tidal dissipation takes place. This resulted in larger-amplitude tides in the deep ocean and enhanced tidal conversion to internal waves in the deep ocean (Egbert et al. 2004). Assuming the abyssal stratification was the same during the LGM as in the present day, and taking into account the enhanced abyssal mixing, there was only a small impact on the paleocirculation (Montenegro et al. 2007). That study concluded that the changes to the ocean's basin shape due to sea level change had a much stronger impact on the circulation than changing the mixing. This conclusion further confirms that variability in the tidal forcing is unlikely to lead to significant millennial-time-scale climate variability (Keeling and Whorf 1997, 2000; Munk et al. 2002). However, we leave open the possibility that time-varying mixing in shallow seas is important (Jochum and Potemra 2008), and perhaps tidal cycles in mixing may modulate the climate on shorter time scales ranging from the spring-neap to 18 6-yr nodal modulations (Loder and Garrett 1978; Ffield and Gordon 1996; Yasuda et al. 2006; Ray 2007).

Acknowledgments. The author gratefully acknowledges assistance and helpful discussions with Gokhan Danabasoglu, Keith Lindsay, Bill Large, Steve Yeager, Frank Bryan, and Nancy Norton. Louis St. Laurent, Andreas Thurnherr, and Stephen Griffies provided thorough reviews of the manuscript and gave valuable suggestions and clarifications. This work was supported by the National Science Foundation under Grants ATM 02-00929 and OCE 02-41061.

The model integrations were performed at the National Center for Atmospheric Research, which is supported by the National Science Foundation. The Community Climate System Model project is supported by the Directorate for Geosciences of the National Science Foundation and the Office of Biological and Environmental Research of the U.S. Department of Energy. The tidally driven internal wave conversion dataset is available from the author, and is available as part of the standard CCSM release from NCAR.

\section{REFERENCES}

Alford, M. H., 2001: Internal swell generation: The spatial distribution of energy flux from the wind to mixed layer nearinertial motions. J. Phys. Oceanogr., 31, 2359-2368.

—, J. A. MacKinnon, Z. Zhao, R. Pinkel, J. Klymak, and T. Peacock, 2007: Internal waves across the Pacific. Geophys. Res. Lett., 34, L24601, doi:10.1029/2007GL031566.

Arbic, B. K., S. T. Garner, R. W. Hallberg, and H. L. Simmons, 2004: The accuracy of surface elevations in forward global barotropic and baroclinic tide models. Deep-Sea Res. II, 51, 3069-3101, doi:10.1016/j.dsr2.2004.09.014.

Arneborg, L., 2002: Mixing efficiencies in patchy turbulence. J. Phys. Oceanogr., 32, 1496-1506.

Bryan, F. O., 1987: Parameter sensitivity of primitive equation ocean general circulation models. J. Phys. Oceanogr., 17, 970-985.

Bryan, K., and L. J. Lewis, 1979: A water mass model of the world ocean. J. Geophys. Res., 84, 2503-2517.

Carrère, L., and F. Lyard, 2003: Modeling the barotropical response of the global ocean to atmospheric wind and pressure forcing-Comparisons with observations. Geophys. Res. Lett., 30, 1275, doi:10.1029/2002GL016473.

Collins, W. D., and Coauthors, 2006: The Community Climate System Model version 3 (CCSM3). J. Climate, 19, 2122-2143.

Cummins, P. F., G. Holloway, and A. E. Gargett, 1990: Sensitivity of the GFDL ocean general circulation model to a parameterization of the vertical diffusion. J. Phys. Oceanogr., 20, $817-830$

Cunningham, S. A., S. G. Alderson, B. A. King, and M. A. Brandon, 2003: Transport and variability of the Antarctic Circumpolar Current in Drake Passage. J. Geophys. Res., 108, 8084, doi:10.1029/2001JC001147.

Danabasoglu, G., W. G. Large, J. J. Tribbia, P. R. Gent, B. P. Briegleb, and J. C. McWilliams, 2006: Diurnal coupling in the tropical oceans of CCSM3. J. Climate, 19, 2347-2365.

Egbert, G. D., and R. D. Ray, 2000: Significant dissipation of tidal energy in the deep ocean inferred from satellite altimeter data. Nature, 405, 775-778, doi:10.1038/35015531.

- - - and B. G. Bills, 2004: Numerical modeling of the global semidiurnal tide in the present day and in the last glacial maximum. J. Geophys. Res., 109, C03003, doi:10.1029/ 2003JC001973.

England, M. H., 1995: The age of water and ventilation timescales in a global ocean model. J. Phys. Oceanogr., 25, 2756-2777.

Ffield, A., and A. L. Gordon, 1996: Tidal mixing signatures in the Indonesian Seas. J. Phys. Oceanogr., 26, 1924-1937.

Ganachaud, A., 2003: Large-scale mass transports, water mass formation, and diffusivities estimated from World Ocean Circulation Experiment (WOCE) hydrographic data. J. Geophys. Res., 108, 3213, doi:10.1029/2002JC001565.

— , and C. Wunsch, 2000: Improved estimates of global ocean circulation, heat transport and mixing from hydrographic data. Nature, 408, 453-457, doi:10.1038/35044048.

Gargett, A. E., 1984: Vertical eddy diffusivity in the ocean interior. J. Mar. Res., 42, 359-393.

Garrett, C., and W. H. Munk, 1975: Space-time scales of internal waves: A progress report. J. Geophys. Res., 80, 291-297.

- and L. St. Laurent, 2002: Aspects of deep ocean mixing. J. Oceanogr., 58, 11-24, doi:10.1023/A:1015816515476.

— ocean. Annu. Rev. Fluid Mech., 39, 57-87, doi:10.1146/ annurev.fluid.39.050905.110227.

Gent, P. R., and J. C. McWilliams, 1990: Isopycnal mixing in ocean circulation models. J. Phys. Oceanogr., 20, 150-155.

- W. G. Large, and F. O. Bryan, 2001: What sets the mean transport through Drake Passage? J. Geophys. Res., 106, 2693-2712, doi:10.1029/2000JC900036.

_ , F. O. Bryan, G. Danabasoglu, K. Lindsay, D. Tsumune, M. W. Hecht, and S. C. Doney, 2006: Ocean chlorofluorocarbon and heat uptake during the twentieth century in the CCSM3. J. Climate, 19, 2366-2381. 
Gille, S. T., M. M. Yale, and D. T. Sandwell, 2000: Global correlation of mesoscale ocean variability with seafloor roughness from satellite altimetry. Geophys. Res. Lett., 27, 1251-1254, doi:10.1029/1999GL007003.

Gregg, M. C., 1977: Variations in the intensity of small-scale mixing in the main thermocline. J. Phys. Oceanogr., 7, 436-454.

- 1987: Diapycnal mixing in the thermocline: A review. J. Geophys. Res., 92, 5249-5286.

1989: Scaling turbulent dissipation in the thermocline. J. Geophys. Res., 94, 9686-9698.

_ T. B. Sanford, and D. P. Winkel, 2003: Reduced mixing from the breaking of internal waves in equatorial waters. Nature, 422, 513-515.

Griffies, S. M., R. C. Pacanowski, and R. W. Hallberg, 2000: Spurious diapycnal mixing associated with advection in a z-coordinate ocean model. Mon. Wea. Rev., 128, 538-564.

Hasumi, H., and N. Suginohara, 1999: Effects of locally enhanced vertical diffusivity over rough bathymetry on the world ocean circulation. J. Geophys. Res., 104, 23 367-23 374, doi:10.1029/ 1999JC900191.

Hibiya, T., M. Nagasawa, and Y. Niwa, 2006: Global mapping of diapycnal diffusivity in the deep ocean based on the results of expendable current profiler (XCP) surveys. Geophys. Res. Lett., 33, L03611, doi:10.1029/2005GL025218.

Hirst, A. C., and W. Cai, 1994: Sensitivity of a world ocean GCM to changes in subsurface mixing parameterization. J. Phys. Oceanogr., 24, 1256-1279.

Huang, R. X., 1999: Mixing and energetics of the oceanic thermohaline circulation. J. Phys. Oceanogr., 29, 727-746.

- 2004: Ocean, energy flows in. Encyclopedia of Energy, Vol. 4, Elsevier Inc., 497-509, doi:10.1016/B0-12-176480-X/00053-X.

— , and X. Jin, 2002: Deep circulation in the South Atlantic induced by bottom-intensified mixing over the midocean ridge. J. Phys. Oceanogr., 32, 1150-1164.

Jayne, S. R., and L. C. St. Laurent, 2001: Parameterizing tidal dissipation over rough topography. Geophys. Res. Lett., 28, 811-814, doi:10.1029/2000GL012044.

— - _ and S. T. Gille, 2004: Connections between ocean bottom topography and Earth's climate. Oceanography, 17, $65-74$.

Jochum, M., 2009: Impact of latitudinal variations in vertical diffusivity on climate simulations. J. Geophys. Res., 114, C01010, doi:10.1029/2008JC005030.

_ Sea diffusivity in the Community Climate System Model. J. Climate, 21, 6445-6454.

Keeling, C. D., and T. P. Whorf, 1997: Possible forcing of global temperature by oceanic tides. Proc. Natl. Acad. Sci. USA, 94, 8321-8328.

— and - 2000: The 1,800 year oceanic tidal cycle: A possible cause of rapid climate change. Proc. Natl. Acad. Sci. USA, 97, 3814-3819.

Kunze, E., E. Firing, J. M. Hummon, T. K. Chereskin, and A. M. Thurnherr, 2006: Global abyssal mixing inferred from lowered ADCP shear and CTD strain profiles. J. Phys. Oceanogr., 36, 1553-1576.

Large, W., and S. Yeager, 2004: Diurnal to decadal global forcing for ocean and sea ice models: The data sets and flux climatologies. National Center for Atmospheric Research Tech. Rep. NCAR/TN460 + STR, 111 pp.

- and _ 2009: The global climatology of an interannually varying air-sea flux data set. Climate Dyn., 33, 341-364, doi:10.1007/s00382-008-0441-3.
J. C. McWilliams, and S. C. Doney, 1994: Oceanic vertical mixing: A review and a model with nonlocal boundary layer parameterization. Rev. Geophys., 32, 363-403, doi:10.1029/ 94RG01872.

, G. Danabasoglu, S. Doney, and J. C. McWilliams, 1997: Sensitivity to surface forcing and boundary layer mixing in a global ocean model: Annual mean climatology. J. Phys. Oceanogr., 27, 2418-2447.

Ledwell, J. R., A. J. Watson, and C. S. Law, 1993: Evidence for slow mixing across the pycnocline from an open-ocean tracer-release experiment. Nature, 364, 701-703, doi:10.1038/ $364701 \mathrm{a} 0$

,$- \ldots$, and — 1998: Mixing of a tracer in the pycnocline. J. Geophys. Res., 103, 21 499-21 529.

, E. T. Montgomery, K. L. Polzin, L. C. St. Laurent, R. W. Schmitt, and J. M. Toole, 2000: Evidence of enhanced mixing over rough topography in the abyssal ocean. Nature, 403, 179-182, doi:10.1038/35003164.

Levitus, S., T. Boyer, M. Conkright, D. Johnson, T. O'Brien, J. Antonov, C. Stephens, and R. Gelfeld, 1998: Introduction. Vol. 1, World Ocean Database 1998, NOAA Atlas NESDIS $18,346 \mathrm{pp}$.

Loder, J. W., and C. Garrett, 1978: The 18.6 year cycle of sea surface temperature in shallow seas due to variations in tidal mixing. J. Geophys. Res., 83, 1967-1970.

MacKinnon, J. A., and K. B. Winters, 2005: Subtropical catastrophe: Significant loss of low-mode tidal energy at $28.9^{\circ}$. Geophys. Res. Lett., 32, L15605, doi:10.1029/2005GL023376.

_ , T. M. S. Johnston, and R. Pinkel, 2008: Strong transport and mixing of deep water through the Southwest Indian Ridge. Nature Geosci., 1, 755-758.

Marotzke, J., 1997: Boundary mixing and the dynamics of threedimensional thermohaline circulations. J. Phys. Oceanogr., 27, 1713-1728.

McFarlane, N. A., 1987: The effect of orographically excited gravity wave drag on the general circulation of the lower stratosphere and troposphere. J. Atmos. Sci., 44, 1775-1800.

Montenegro, Á., M. Eby, A. J. Weaver, and S. R. Jayne, 2007: Response of a climate model to tidal mixing parameterization under present day and Last Glacial Maximum conditions. Ocean Modell., 19, 125-137, doi:10.1016/j.ocemod.2007.06.009.

Morris, M., M. H. Hall, L. C. St. Laurent, and N. G. Hogg, 2001: Abyssal mixing in the Brazil Basin. J. Phys. Oceanogr., 31, 3331-3348.

Munk, W. H., 1966: Abyssal recipes. Deep-Sea Res., 13, 707-730.

— , and C. Wunsch, 1998: Abyssal recipes II: Energetics of tidal and wind mixing. Deep-Sea Res., 45, 1977-2010, doi:10.1016/ S0967-0637(98)00070-3.

_ - M. Dzieciuch, and S. R. Jayne, 2002: Millennial climate variability: Is there a tidal connection? J. Climate, 15, 370-385.

Naveira Garabato, A. C., K. L. Polzin, B. A. King, K. J. Heywood, and M. Visbeck, 2004: Widespread intense turbulent mixing in the Southern Ocean. Science, 303, 210-213, doi:10.1126/ science1090929.

_ D. P. Stevens, A. J. Watson, and W. Roether, 2007: Shortcircuiting of the overturning circulation in the Antarctic circumpolar current. Nature, 447, 194-197, doi:10.1038/ nature 05832 .

Osborn, T. R., 1980: Estimates of the local rate of vertical diffusion from dissipation measurements. J. Phys. Oceanogr., 10, 83-89.

Palmer, T. N., G. J. Shutts, and R. Swinbank, 1986: Alleviation of a systematic westerly bias in general circulation and numerical 
weather prediction models through an orographic gravity wave drag parameterization. Quart. J. Roy. Meteor. Soc., 112, 1001-1039.

Peltier, W. R., and C. P. Caulfield, 2003: Mixing efficiency in stratified shear flows. Annu. Rev. Fluid Mech., 35, 135-167.

Polzin, K. L., J. M. Toole, J. R. Lewell, and R. W. Schmitt, 1997: Spatial variability of turbulent mixing in the abyssal ocean. Science, 276, 93-96, doi:10.1126/science.276.5309.93.

Ray, R. D., 2007: Decadal climate variability: Is there a tida connection? J. Climate, 20, 3542-3560.

Saenko, O. A., 2006: The effect of localized mixing on the ocean circulation and time-dependent climate change. J. Phys. Oceanogr., 36, 140-160.

— enhanced mixing on the global ocean circulation. J. Phys. Oceanogr., 35, 826-834.

Samelson, R. M., 1998: Large-scale circulation with locally enhanced vertical mixing. J. Phys. Oceanogr., 28, 712-726.

Scott, J. R., and J. Marotzke, 2002: The location of diapycnal mixing and the meridional overturning circulation. J. Phys. Oceanogr., 32, 3578-3595.

Simmons, H. L., S. R. Jayne, L. C. St. Laurent, and A. J. Weaver, 2004: Tidally driven mixing in a numerical model of the ocean general circulation. Ocean Modell., 6, 245-263, doi:10.1016/ S1463-5003(03)00011-8.

Smith, R. D., and P. R. Gent, 2002: Reference manual for the Parallel Ocean Program (POP) ocean component of the Community Climate System Model (CCSM2.0 and 3.0). Tech. Rep. LA-UR-02-2484, Los Alamos National Laboratory, 75 pp.

— J. K. Dukowicz, and R. C. Malone, 1992: Parallel ocean general circulation modeling. Physica D, 60, 38-61, doi:10.1016/0167-2789(92)90225-C.

Smith, W. H. F., and D. T. Sandwell, 1997: Global sea floor topography from satellite altimetry and ship depth soundings. Science, 277, 1956-1962, doi:10.1126/science.277.5334.1956.

Steele, M., R. Morley, and W. Ermold, 2001: PHC: A global ocean hydrography with a high-quality Arctic Ocean. J. Climate, 14, 2079-2087.

St. Laurent, L. C., and C. Garrett, 2002: The role of internal tides in mixing the deep ocean. J. Phys. Oceanogr., 32, 2882-2899.
, and J. D. Nash, 2004: An examination of the radiative and dissipative properties of deep ocean internal tides. Deep-Sea Res. II, 51, 3029-3042, doi:10.1016/j.dsr2.2004.09.008.

— , and H. L. Simmons, 2006: Estimates of power consumed by mixing in the ocean interior. J. Climate, 19, 4877-4890.

—, J. M. Toole, and R. W. Schmitt, 2001: Buoyancy forcing by turbulence above rough topography in the abyssal Brazil Basin. J. Phys. Oceanogr., 31, 3476-3495.

—, H. L. Simmons, and S. R. Jayne, 2002: Estimates of tidally driven enhanced mixing in the deep ocean. Geophys. Res. Lett., 29, 2106, doi:10.1029/2002GL015633.

Stommel, H., and A. B. Arons, 1960: On the abyssal circulation of the world ocean-I. Stationary planetary flow patterns on a sphere. Deep-Sea Res., 6, 140-154, doi:10.1016/01466313(59)90065-6.

Talley, L. D., 2003: Shallow, intermediate, and deep overturning components of the global heat budget. J. Phys. Oceanogr., 33, 530-560.

_ J. L. Reid, and P. E. Robbins, 2003: Data-based meridional overturning streamfunctions for the global ocean. J. Climate, 16, 3213-3226.

Thurnherr, A. M., L. C. St. Laurent, K. G. Speer, J. M. Toole, and J. R. Ledwell, 2005: Mixing associated with sills in a canyon on the midocean ridge flank. J. Phys. Oceanogr., 35, 1370-1381.

U.S. Department of Commerce, 2006: 2-minute Gridded Global Relief Data (ETOPO2v2). National Oceanic and Atmospheric Administration, National Geophysical Data Center. [Available online at http://www.ngdc.noaa.gov/mgg/fliers/06mgg01.html.]

von Storch, J. S., H. Sasaki, and J. Marotzke, 2007: Wind-generated power input to the deep ocean: An estimate using a $1 / 10^{\circ}$ general circulation model. J. Phys. Oceanogr., 37, $657-672$.

Wunsch, C., and R. Ferrari, 2004: Vertical mixing, energy, and the general circulation of the oceans. Annu. Rev. Fluid Mech., 36, 281-314, doi:10.1146/annurev.fluid.36.050802.122121.

Yasuda, I., S. Osafune, and H. Tatebe, 2006: Possible explanation linking 18.6 year period nodal tidal cycle with bi-decadal variations of ocean and climate in the North Pacific. Geophys. Res. Lett., 33, L08606, doi:10.1029/2005GL025237. 